


\section{A Orientación editorial}

\section{Enfoque y alcance}

La Revista de Arquitectura (ISSN 1657-0308 Impresa y E-ISSN 2357-626X en línea) es una publicación seriada de acceso abierto, arbitrada mediante revisión por pares (doble ciego) e indexada, en donde se publican resultados de investigación originales e inéditos.

Está dirigida a la comunidad académica y profesional de las áreas afines a la disciplina. Es editada por la Facultad de Diseño y el Centro de Investigaciones (CIFAR) de la Universidad Católica de Colombia en Bogotá (Colombia).

La principal área científica a la que se adscribe la Revista de Arquitectura según la OCDE es:

Gran área: 6. Humanidades

Área: 6.D. Arte

Disciplina: 6D07. Arquitectura y Urbanismo

También se publican artículos de las disciplinas como 2A02, Ingeniería arquitectónica; 5G03, Estudios urbanos (planificación y desarrollo); 6D07, Diseño.

Los objetivos de la Revista de Arquitectura son:

- Promover la divulgación y difusión del conocimiento generado a nivel local, nacional e internacional

- Conformar un espacio para la construcción de comunidades académicas y la discusión en torno a las secciones definidas.

- Fomentar la diversidad institucional y geográfica de los autores que participan en la publicación.

- Potenciar la discusión de experiencias e intercambios científicos entre investigadores y profesionales.

- Contribuir a la visión integral de la arquitectura, por medio de la concurrencia y articulación de las secciones mediante la publicación de artículos de calidad.

- Publicar artículos originales e inéditos que han pasado por revisión de pares, para asegurar que se cumplen las normas éticas, de calidad, validez científica, editorial e investigativa.

- Fomentar la divulgación de las investigaciones y actividades desarrolladas en la Universidad Católica de Colombia.
Palabras clave de la Revista de Arquitectura: arquitectura, diseño, educación arquitectónica, proyecto y construcción, urbanismo.

Idiomas de publicación: español, inglés, portugués y francés. Título abreviado: Rev. Arquit.

\section{Titulo corto: RevArq}

\section{Políticas de sección}

La revista se estructura en tres secciones correspondientes a las líneas de investigación activas y aprobadas por la institución, y dos complementarias, que presentan dinámicas propias de la Facultad de Diseño y las publicaciones relacionadas con la disciplina.

Cultura y espacio urbano. En esta sección se publican los artículos que se refieren a fenómenos sociales en relación con el espacio urbano, atendiendo aspectos de la historia, el patrimonio cultural y físico, y la estructura formal de las ciudades y el territorio.

Proyecto arquitectónico y urbano. En esta sección se presentan artículos sobre el concepto de proyecto, entendido como elemento que define y orienta las condiciones proyectuales que devienen en los hechos arquitectónicos o urbanos, y la forma como estos se convierten en un proceso de investigación y nuevo de conocimiento. También se presentan proyectos que sean resultados de investigación, los cuales se validan por medio de la ejecución y transformación en obra construida del proceso investigativo. También se contempla la publicación de investigaciones relacionadas con la pedagogía y didáctica de la arquitectura, el urbanismo y el diseño.

Tecnología, medioambiente y sostenibilidad. En esta sección se presentan artículos acerca de sistemas estructurales, materiales y procesos constructivos, medioambiente y gestión, relacionados con los entornos social-cultural, ecológico y económico.

Desde la Facultad. En esta sección se publican artículos generados en la Facultad de Diseño, relacionados con las actividades de docencia, extensión, formación en investigación o internacionalización, las cuales son reflejo de la dinámica y de las actividades realizadas por docentes, estudiantes y egresados; esta sección no puede superar el $20 \%$ del contenido.

Textos. En esta sección se publican reseñas, traducciones y memorias de eventos relacionados con las publicaciones en Arquitectura y Urbanismo.

\section{A Frecuencia de publicación}

Desde 1999 y hasta el 2015, la Revista de Arquitectura publicó un volumen al año, a partir del 2016 se publicarán dos números por año en periodo anticipado, enero-junio y julio-diciembre, pero también maneja la publicación anticipada en línea de los artículos aceptados (versión Post-print del autor).

La Revista de Arquitectura se divulga mediante versiones digitales (PDF, HTML, XML) e impresas con un tiraje de 700 ejemplares, los tiempos de producción de estas versiones dependerán de los cronogramas establecidos por la editorial.

Los tiempos de recepción-revisión-aceptación pueden tardar entre seis y doce meses dependiendo del flujo editorial de cada sección y del proceso de revisión y edición adelantado.

Con el usuario y contraseña asignados, los autores pueden ingresar a la plataforma de gestión editorial y verificar el estado de revisión, edición o publicación del artículo.
A Canje

La Revista de Arquitectura está interesada en establecer canje con publicaciones académicas, profesionales o científicas del área de Arquitectura y Urbanismo, como medio de reconocimiento y discusión de la producción científica en el campo de acción de la publicación.

\section{Mecanismo}

Para establecer canje por favor descargar diligenciar y enviar el formato: RevArq FP20 Canjes

Universidad Católica de Colombia (2016, julio-diciembre). Revista de Arquitectura, 18(2), 1-136. Doi: 10.14718

ISSN: 1657-0308 E-ISSN: 2357-626X

Especificaciones:

Formato: $34 \times 24 \mathrm{~cm}$

Papel: Mate $115 \mathrm{~g}$

Tintas: Negro y policromía

\section{(A) Contacto}

Dirección postal:

Avenida Caracas No. 46-72. Universidad Católica de Colombia. Bogotá D.C.(Colombia)

Código postal: 111311

Facultad de Diseño, Centro de Investigaciones (CIFAR). Sede El Claustro. Bloque "L", 4 piso, Diag. 46a No. 15b-10. Editor, Arq. César Andrés Eligio Triana

Teléfonos: +57 (1) 3277300 - 3277333

Ext. 3109; 3112 o 5146

Fax: +57 (1) 2858895

Correo electrónico:

revistadearquitectura@ucatolica.edu.co cifar@ucatolica.edu.co

\section{Página WEB}

www.ucatolica.edu.co vínculo Revistas científicas http://publicaciones.ucatolica.edu.co/revistas-cientificas http://editorial.ucatolica.edu.co/ojsucatolica/revistas ucatoli$\mathrm{ca} /$ index.php/RevArq 


\section{CONTENDO}

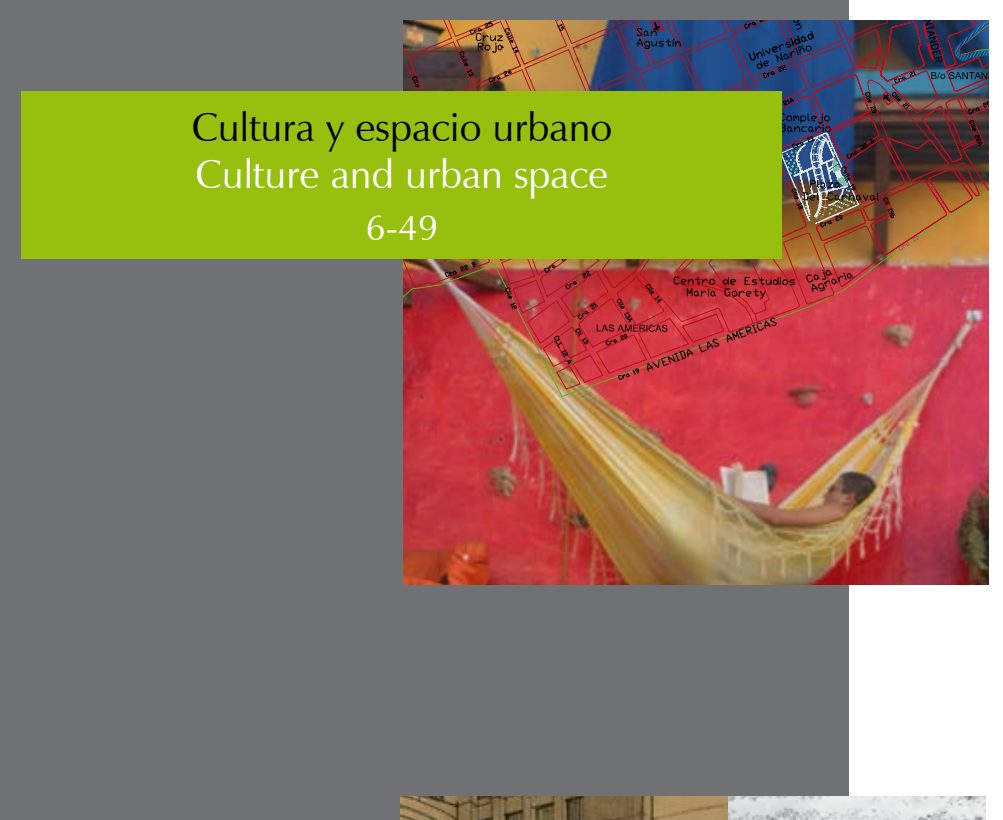

Estructura de indicadores de habitabilidad del espacio público en ciudades latinoamericanas

Pablo Páramo, Andrea Burbano, Diana Fernández-Londoño Pág. 6

Além do público/privado

Intervenções temporárias e criação de

espaços coletivos no Rio de Janeiro

Adriana Sansão-Fontes, Aline Couri-Fabião

Pág. 27

Conservar o renovar: dinámicas de construcción en el centro histórico de tres ciudades intermedias patrimoniales

Una mirada a través de las licencias urbanísticas

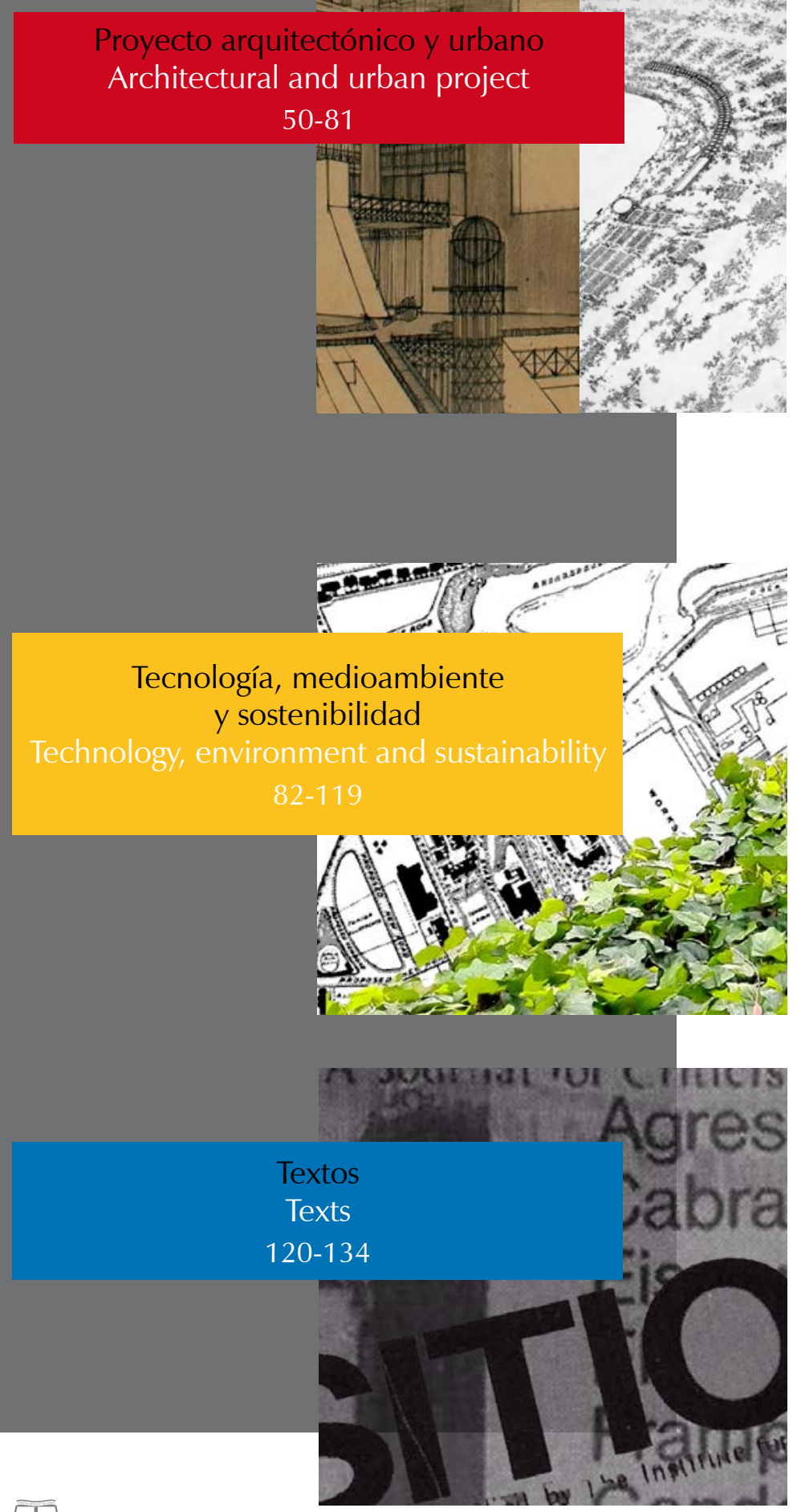

El paisaje del hábitat horizontal:

la Unidad del Tuscolano en Roma y el Poblado de Entrevías en Madrid

Federico Colella

Evolución paralela del relato fílmico y la arquitectura de los cines entre 1900 y 1930

Atención especial al caso español

Ana C. Lavilla-Iribarren

El plan, acto mesiánico del proyectista

La situación histórica del diseño en

la utopía modernizante

Valentina Mejía-Amézquita, Adolfo León Grisales-Vargas Pág. 71

Resiliencia a inundaciones:

nuevo paradigma para el diseño urbano

Luis Fernando Molina-Prieto

Pág. 82

Acceso solar en la arquitectura y la ciudad

Aproximación histórica

Ricardo Franco-Medina, Pedro Juan Bright-Samper

Pág. 95

\section{Campus universitario sustentable}

Lina Johanna Zapata-González, Andrés Quiceno-Hoyos, Luisa Fernanda Tabares-Hidalgo

La crítica arquitectónica como objeto de investigación [La critique architecturale, objet de recherche]

Hélène Jannière

Traductores: Andrés Ávila-Gómez, Diana Carolina Ruiz Pág. 120 


\title{
El plan, acto mesiánico del proyectista \\ La situación histórica del diseño en la utopía modernizante
}

\author{
Valentina Mejía-Amézquita, Adolfo León Grisales-Vargas \\ Universidad de Caldas, Manizales (Colombia) \\ Grupo de investigación en Filosofía y Cultura
}

\section{Mejía-Amézquita, V. \& Grisales-Var- gas, A. (2016). El plan, acto mesiánico del proyectista. L situación histórica del dise- ño en la utopía modernizan- te. Revista de Arquitectura, I8(2), $71-81$. doi:10.14718/ RevArq.2016.18.2.7}

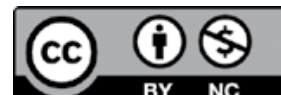

htp://dxdoiorg/10.14718/Revtrq2016.18.27

\section{Valentina Mejía-Amézquita}

Arquitecta, Universidad Nacional de Colombia (Colombia) Doctora en Diseño y Creación, Universidad de Caldas (Colombia). Estudios de doctorado en Teoría e Historia de la arquitectura, UPC de Barcelona.

Magíster en Filosofía, Universidad de Caldas (Colombia).

Especialista en gestión inmobiliaria, Universidad Nacional de Colombia (Colombia).

Directora de la Facultad de Diseño Industrial, Universidad Pontificia Bolivariana.

Investigadora del grupo Filosofía y Cultura, Universidad de Caldas y del GED, Universidad Pontificia Bolivariana.

http://orcid.org/0000-0002-7668-5320

valentina.mejiaa@upb.edu.co

\section{Adolfo León Grisales-Vargas}

Filósofo, Universidad de Antioquia.

Maestría en Filosofía, Universidad de Antioquia

Doctor en Filosofía, Pontificia Universidad Javeriana.

Docente y director del grupo de investigación Filosofía y Cultura, Universidad de Caldas

http://orcid.org/0000-0002-4385-858X

adolfo.grisales@ucaldas.edu.co

\section{Resumen}

Se retoman los orígenes disciplinados del diseño desde la dicotomía entre las lógicas creativas del académico y las de un hombre común sin formación académica como proyectista. El ejercicio investigativo nos ha permitido avizorar que las prácticas culturales "incorporadas" y las apuestas colectivas, entendidas como intención consentida por un grupo social, pueden ser comprendidas como el sustrato que determina las lógicas del quehacer proyectivo transformador de mundo. Estos supuestos fueron determinantes en el momento de establecer la postura que habría de definir el diseño como una "tercera área del saber humano" desde el siglo XX hasta hoy. El resultado de esta pesquisa invita a asumir una postura crítica frente al rol del diseño visto como una disciplina que oscila entre el mundo de lo ideado desde las lógicas del proyectista disciplinado y el mundo de lo realizado en manos del obrador, en el escenario de la multiplicidad de coexistencias de facto que yuxtaponen lo uno con lo otro en lugares precisos y en tiempos determinados.

Palabras clave: arquitectura moderna, creación, crítica arquitectónica, diseño, proyecto cultural.

The plan, a messianic act of the project architect. The historical situation of design in the modernizing utopia

\section{Abstract}

The disciplinary origins of design are resumed based on the dichotomy between the creative logics of an academic and the logics of a common man without academic training as a project architect. The investigative exercise has allowed to recognize that "built-in" cultural practices and collective bets, understood as an intention approved by a social group, can be seen as the substrate that determines the logics of the projective task that transforms the world. These assumptions were decisive at the moment of establishing the position that would define design as a "third area of human knowledge" from the twentieth century until today. The result of this research invites the reader to take a critical stance against the role of design seen as a discipline that oscillates between what is conceived from the logic of the trained project architect and what is completed by the hands of the worker, in a scenario of multiplicity of de facto coexistences that juxtapose one with the other in concrete places and in determined times.

Keywords: Modern architecture, creation, architectural criticism, design, cultural project.
Evaluado: octubre 04/2016

\section{Introducción}

En el marco del desarrollo de la investigación acerca de las maneras de obrar arquitectura cotidiana por el hombre no disciplinado en el saber proyectual, nos vimos abocados a revivir la discusión alrededor de las lógicas disciplinares frente a las del obrar incorporado como práctica cultural. El presente artículo hace parte del estadio intermedio de dicha investigación, remitiendo resultados sobre la ontología del plan y del proyecto como escenarios que espacializan y configuran un territorio común entre ambas. Este documento corresponde a uno de los primeros resultados de la fase inicial del proceso de revisión documental vinculada a la investigación doctoral sobre la disciplina del Diseño, adscrita al proyecto Arquitectura y diseño, del grupo de investigación Filosofía y Cultura de la Universidad de Caldas, en la línea de investigación de Teoría del habitar, titulado "La casa vivida" ${ }^{1}$, que ha permitido aunar esfuerzos entre la Universidad de Caldas y Colciencias en el proceso de apoyar la formación de doctores en el país.

Comencemos por recordar que los famosos diálogos entre Sócrates y Glaucón contenidos en la República de Platón (c390 a 385 a. C.) (1994), han sido determinantes en el desarrollo cultural de Occidente por casi dos mil quinientos años. En uno de sus apartados se detienen en un asunto de especial interés para el quehacer artístico y proyectual; es el libro Décimo, en el cual se ocupa del llamado "arte de la imitación", y frente al cual Sócrates intenta descifrar la naturaleza de los productos derivados del actuar divino y del proceder humano.

Valiéndose de su singular argucia, y de un método ordinario de indagación, conduce a Glaucón a cuestionarse sobre la veracid ad del mundo, asunto que Platón considera reside en la elaboración mental de las ideas para convertirlas

1 Este artículo se deriva del proyecto de investigación "La casa vivida. Una aproximación al diseño a partir de las maneras de obrar arquitectura cotidiana en San José - Manizales, Colombia", un ejercicio académico entre Colciencias (con Valentina Mejía Amézquita mientras se hallaba en formación doctoral en Diseño y Creación gracias a una beca de Colciencias) y la Vicerrectoría de Investigaciones de la Universidad de Caldas (Cod.0878015), proyecto liderado por el profesor Adolfo León Grisales Vargas. 
en el único mundo real posible y que solo puede ser concebido por la genialidad del demiurgo. Del mismo modo, encamina al lego a preguntarse por la falacia que habita en la materialidad imperfecta de las cosas que se le presentan engañosas ante la fragilidad de sus sentidos, en especial aquellas que son resultado de la imitación.

Sócrates, entonces, da cuenta de tres clases de seres que son artífices de todo lo que existe. El primero, sin duda, es el dios creador que, en su condición "productora" de todas las cosas verdaderas, ya sea por voluntad o necesidad, hace posible la esencia. Nada existe si él no lo ha ideado. El segundo, el artesano o hacedor que, como "obrador", solo puede representar, a través de la materialidad de un objeto específico, lo que realmente existe, es decir, el ser facultado para encarnar la idea en una expresión físicamente imperfecta que figura ser verídica. El tercero, el imitador, que se ocupa de replicar la apariencia de lo que per se no es real y que, según Platón, está no solo alejado en tres grados de la naturaleza de la verdad, es el copista de un mundo previamente artificializado y frente al cual trata de ser fiel con fina argucia, llevando a una tercera irrealidad lo que la experiencia de sus sentidos le muestra y él, con cierto descaro, pretende negar y hacer aparecer como verdadero.

La intención de situar esta reflexión al mostrar rápidamente lo que es la visión del mundo posible o lo que también ha sido considerado como un dualismo metafísico esbozado por Platón, se ata a la necesidad de relocalizar el diseño como una disciplina que oscila entre el mundo de lo

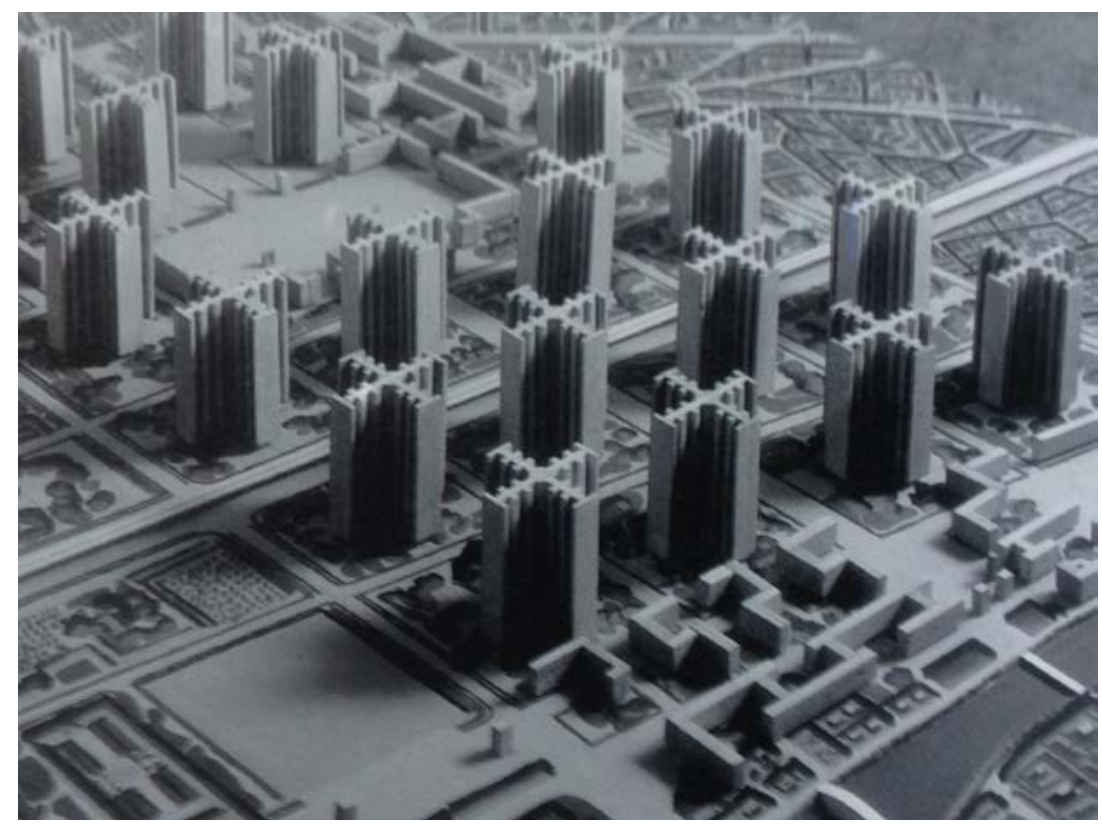

ideado y el mundo de lo obrado, demanda que ha sido reiteradamente emergente en el trabajo investigativo sobre el diseño en el marco de la proyectación de la urbe actual y que cobija este resultado parcial.

La reiterada emergencia nos hace pensar que el oficio diseñístico de concebir el mundo, como lo define Saikaly (2005, p. 3), puede superar la noción reproductora platónica, es decir, el oficio del genio creador investido de un halo mágico bajo el cual manifiesta el demiurgo su actuar divino y cuya apuesta de mundo es la utopía, por ser lo más próximo a la verdad absoluta, logrando en la Modernidad su máxima expresión idealizada. Esta superación óntica podría instalarnos en un escenario de reterritorialización de un quehacer generador de mundo que oscila entre la realidad del proyecto, exitoso o malogrado, como lo contemplaba ya Otl Aicher (1994), y una praxis que se manifiesta en el escenario de la multiplicidad de coexistencias de facto que yuxtaponen la diversidad de actores que median lo ideado con lo realizado en lugares precisos localizables y en tiempos determinados medibles. El asunto nos sitúa frente a una nueva postura del diseño en su necesidad actual de repensarse como disciplina y accionar integrador que hace mundo (Figura 1).

\section{Metodología}

Parte de los resultados de la investigación sobre la arquitectura "obrada" por el hombre común se ubica en el escenario de la metateoría de la disciplina del diseño, aunque valga aclarar que esta investigación en su conjunto no solo apunta a las dimensiones discursivas, sino a la transformación del pensamiento puesto en práctica que, para nuestro caso, se concentró en la arquitectura doméstica popular del centro-occidente andino colombiano, debiendo anticipar al lector que los resultados aquí presentados son producto de la fase inicial que determina la manera como habremos de entender el diseño.

La ruta metodológica se basa en una amplia revisión documental de orden teórico, la misma que se subvierte en la polaridad evidenciada paralelamente en el campo que, no olvidemos, no será descrito ni analizado en este trabajo. Lo que sí es cierto es que es la dicotómica experiencia de conocimiento y reconocimiento del saber apropiado, y las maneras de proyectar el mundo espontáneamente, las que nos convocaron a 
poner en estas líneas esta preocupación entre el plan y el proyecto.

El ejercicio teórico se instala en una tercera vía del saber humano, situación que ha sido fuertemente referida desde finales de la década de los setenta y está aún en boga, oscilando entre las apuestas disciplinares que se acunaron en las visiones que abrieron un nuevo horizonte bajo la revolución del siglo XX gracias a las vanguardias y a la modernidad bahuausiana y lecorbusiana $y$, más recientemente, las de la tardomodernidad bajo la tutela y diversidad discursiva de autores como Archer (1979; 1995), Cross $(1982 ; 2011)$ o Buchanan (1998; 2001), solo por citar a unos pocos de los más ampliamente debatidos desde la década de los setenta hasta nuestros días, alrededor del "área de la experiencia humana, la habilidad y el entendimiento que refleja la preocupación del hombre alrededor de lo que lo rodea bajo la luz de sus necesidades materiales y espirituales" (Archer, 1979, p. 17).

Valga aclarar de antemano, que la postura discursiva de la que trata este artículo no es una afrenta a la Modernidad — pues entre otros, debemos reconocer en ella el origen del diseño como saber independiente, o al menos libertario-, ni tampoco es una apología ciega a los discursos más recientes, como los de Archer (1995), Manzini (2009), Forlizzi, Stolterman, Zimmerman (2009) o Hernández (2006) y otros tantos, pues comprendemos que el horizonte hacia donde se dirige la preocupación ontológica parece difuso pero, sin menoscabo ni pretensión de desconocer su aporte, es evidente que se han detenido más en las reflexiones metodológicas que parecen legitimar el diseño como problema de investigación, lo que deja entrever que conceptualmente el asunto de fondo aún se fragua.

La ruta de reflexión parece evidenciar que el quehacer humano que se articula con el diseño podría instalarse en dos espacios opuestos. El primero, que recoge el diseño como el actuar libre y deliberado de proyectar el mundo a su antojo, entiéndase de la mirada del obrar de ese proyectista y que Aicher (1994), de la mano de la Escuela de UIlm, describe de la siguiente manera:

El "hacer es la prolongación del yo hacia el mundo autoorganizado, en el hacer se realiza la persona. Y ello en la medida en que hay implicados un concepto propio y un proyecto propio, y, en una realimentación permanente, se obtienen del hacer conocimientos correctores del concepto y el proyecto.

Solo el hacer creador es verdadero trabajo y verdadero desarrollo de la persona. El proyecto es el signo de la creatividad; solo a través de él se tornan humanos el activismo y el empleo. Un mundo humano presupone un trabajo y un hacer identificados por el proyecto, porque el motivo de la persona aparece en el proyecto (p. 176).

El segundo, donde la razón misma del acto creativo, de la praxis del diseño o su razón activa es, simplemente, la apuesta humanizada por un mundo mejor y que, en nuestra experiencia investigativa puntual, se ha ganado un rol protagónico, pues en la discusión presente el diseño parece, también, orbitar alrededor del ser en el hacer, es decir, el ser como problema antropológico y el hacer como proyecto, donde el diseño tiene sentido como disciplina independiente, creadora y mediadora del hombre y su apuesta de mundo.

El marco conceptual, ciertamente, se blande entre lo que podríamos denominar de lo producible en la voz clásica de Platón, en tanto el diseño como disciplina independiente y emancipada gracias a las vanguardias afirma la dimensión utópica e idealista de la Modernidad, donde el "plan" es el gran modelo de creación en un mundo de corte "universalizante", "aterritorial" y "atemporal", gracias al actuar del genio creador en la línea progresista de una historia ascendente, como lo habría sentenciado Hegel en su odisea progresista del espíritu.

Ahora, en la tensión opuesta estaría el obrar, es decir, la comprensión de la realidad en la lógica del proyecto alcanzado o malogrado que será, a nuestros propósitos de entender el quehacer productor de mundo vía arquitectura, la apuesta real por un universo posible tal y como se sucede, ya sea de la mano del artesano, del operario y del sujeto común que materializan en el escenario legítimo de lo proyectado lo que Michel Foucault denomina la contrariedad de la utopía o en los espacios otros, las heterotopías, los espacios de la alteridad que, en suma, son "las contradicciones míticas y reales del espacio donde vivimos" (2010, p. 23), y que son un resultado del actuar de cualquiera. Resulta sugerente mencionar que Cross (2011) considera que el proyectar es la manera humana de pensar y de intervenir en el cosmos hasta conseguir un mundo artificializado: 


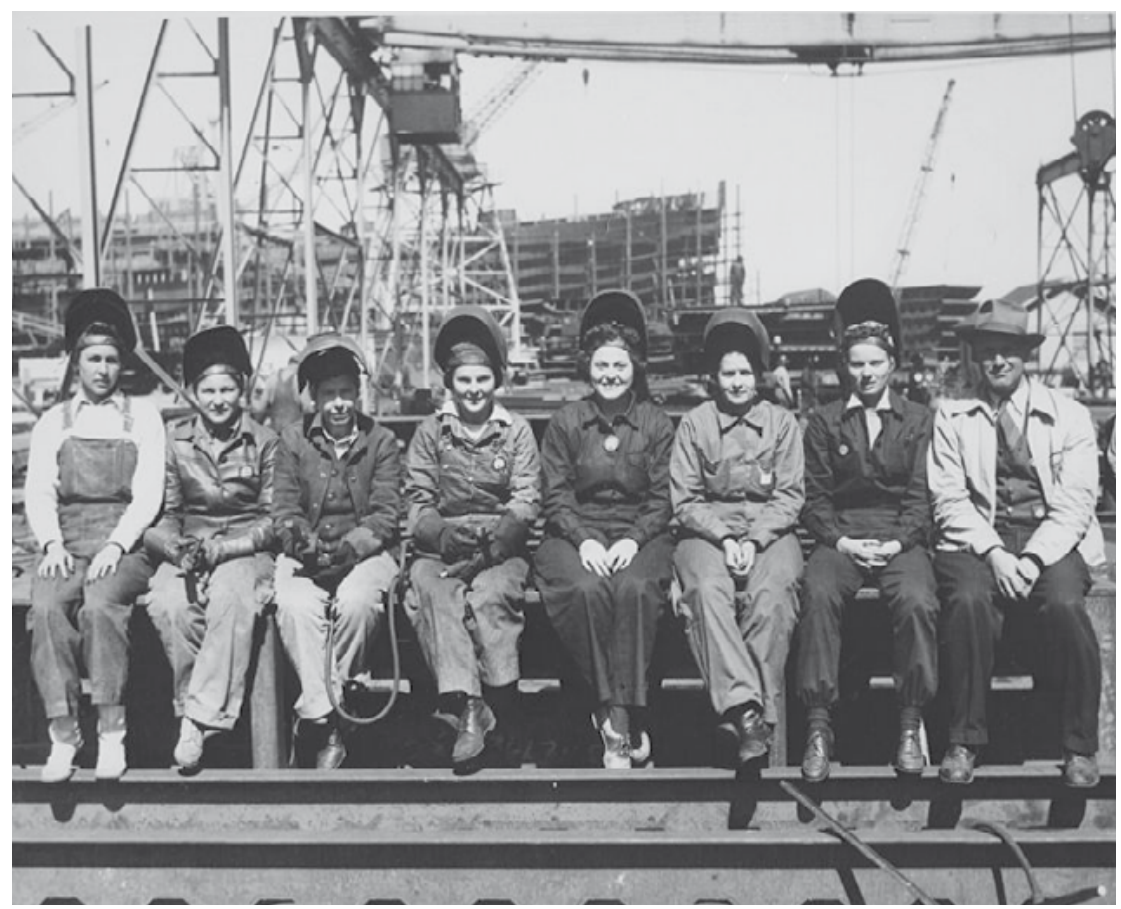

(A) Figura 2. Mujeres soldadoras, en la foto aparece la campeona de soldadura de mujeres de Ingalls

Fuente: National Archives and Records Administration (1943). Dominio público.
Todos podemos - y lo hacemos - diseñar. Todos diseñamos cuando planeamos que algo nuevo suceda, puede ser una nueva versión de un recipiente, arreglos del mobiliario de la sala o una nueva disposición en una página web. La evidencia de diversas culturas alrededor del mundo y de diseños creados por niños como por adultos, sugiere que todos somos capaces de diseñar. Entonces, el pensamiento diseñístico es algo inherente a la cognición humana; es la clave de lo que nos hace humanos (p. 3).

\section{Resultados: del plan al proyecto}

Comencemos por poner de manifiesto que el siglo XX no solo trajo a la ciencia y a las artes, sino también a las disciplinas cuya razón de ser ha sido la proyectación como el diseño, la arquitectura e, incluso, los ya enunciados oficios artesanales, una nueva forma de comprender un mundo que pareció emanciparse de las prácticas anquilosadas del siglo que le antecedía, donde el agotamiento conceptual y estético era innegable, y que parecen recoger el llamado en voz de Giedion (1978), cuando propone que "la mecanización tome el mando" (Figura 2).

Las sociedades, hijas de las revoluciones culturales e, incluso, industriales gestadas en Europa, jamás pudieron siquiera imaginar que terminarían radicalizadas frente al pasado, y que el rechazo al academicismo y el escepticismo histórico darían cabida en los años venideros a una renovación cultural de dimensiones jamás vistas, como bien advierte Subirats (1986) en uno de sus célebres trabajos sugestivamente titulado la Flor y el cristal.

El alzamiento social desbordó las fuerzas del Estado, de las milicias, de los colectivos versados $y$, por supuesto, de los hacedores de mundo que sujetaban sus armas, metafóricamente hablando, en los campos de batalla del arte, y que se valían de las nociones propias de la vida castrense para justificar la postura aguerrida de avanzada de las vanguardias, su visión apocalíptica y, en cierta medida, mesiánica con que esperaban liberarse de las ataduras del pasado y redimir la cultura del letargo en el que se hallaba subsumi$\mathrm{da}$, fue dejando entrever que en el fondo de su lucha lo que subyacía era la utopía de un nuevo orden social que habría de dignificar la condición humana. Para ser claros, iuna quimera!

El naciente siglo XX, que eruditos de la talla de Eric Hobsbawm han descrito como de catástrofes, de oro y, finalmente, de descomposición (1998, p. 22), terminaría siendo convulso, difícil de comprender y determinaría la época actual como ningún otro momento histórico lo había hecho jamás (pp. 15-16), y si las cosas no se hubieran dado así, también es cierto que nuestras "culturas híbridas", como las define García Canclini (2001), no serían lo que son hoy en día.

El siglo XX fue, primeramente, producto de la guerra en todas sus acepciones, del actuar autónomo de los hombres que, por primera vez en la historia de la humanidad y no en nombre de Dios, sublevaron sus conflictos a la dimensión de crisis universal no solo en una, sino en dos oportunidades, con resultados devastadores. La guerra, particularmente la primera de talla global, sería también el símbolo de la estrepitosa caída de la civilización occidental que se había construido sobre los pilares de una burguesía hegemónica que, tras haber superado a la tradicional aristocracia, había configurado una estructura política de índole liberal apalancada en el capitalismo que se movía en la línea histórica de progreso descrita por Hegel (2010), para quien en el discurrir de la vida el precio por la libertad de la humanidad era, entre otros, la guerra misma. Occidente estaba llamado de nuevo a ser el modelo orientador del paradigma del desarrollo humano que, en un momento dado, parecía instalarse como una nueva gran autoridad en contravía de los acosos de corte autoritario que, paradójicamente, tanto reprochó, dándole espacio para establecer las condiciones mínimas de dignidad humana, en todos los escenarios de la existencia.

La postura asumida fue desgarradora, pues la crítica que la Modernidad de los primeros años 
del siglo XX hizo al peso de la tradición y a la cultura estuvo minada por la idea altiva de entenderse a sí misma como única y verdadera; basta solo dar una mirada a los manifiestos libertarios desde el futurismo de Marinetti (2006), el nihilismo vertiginoso del dadaísmo de Tristan Tzara o el delirio emancipador del surrealismo bretoniano (Figura 3). Si uno de sus impulsos más significativos estaba orientado a desatender el pasado por calificarlo como agotado e inconveniente, entonces, cualquier posibilidad de justificación de los supuestos formulados por esa tradición quedaba anulado y se hacía necesario buscar un nuevo camino que, aunque en buena medida ilusorio por lo desmesurado de sus búsquedas totalizantes que solventaran las diferencias históricas y universales, abriera un horizonte cultural perenne a la Europa de posguerra que había quedado sumida en el desconcierto moral absoluto, siendo sustrato de una nueva experiencia estética aún por decantar (Montaner, 1997).

La Modernidad, encarnada en las corrientes ideológicas nacidas para aquel entonces, estaba llamada a refundar, en principio, la noción de un mundo que, en condiciones mínimas, apelara por la libertad, la igualdad y el orden; lo que a ojos de un crítico externo parecería un remedo del alzamiento burgués, de la mano de la naciente clase obrera, a lo acaecido en plena Revolución francesa.

El primer síntoma de transformación cultural sería el nacimiento de las vanguardias artísticas de la mano de la noción vigilante, de arremetida y defensiva, que deriva de la guerra. La acepción tradicional de la palabra "vanguardia", tomada de la vida militar, determinó la postura destructora del pasado; así como la táctica normativa y ordenadora de mundo que habría de direccionar los principios éticos y estéticos de una nueva sociedad y, en consecuencia, de un nuevo arte. Eduardo Subirats (1986), en su reconocido texto sobre las vanguardias modernas, afirma

No, no es por un azar, ni mucho menos una paradoja el que pintores, escultores, poetas, arquitectos y músicos adoptasen en las primeras décadas de nuestro siglo el nombre y la concepción estratégica de la vanguardia para definir una posición nueva de su actividad artística frente a la realidad social que les rodeaba. El problema es algo más profundo. Se trata de una crisis o, más bien, de la visión mejor o peor formulada de un vacío cultural, y de la necesidad de una transformación de los valores de las sociedades europeas, que solo

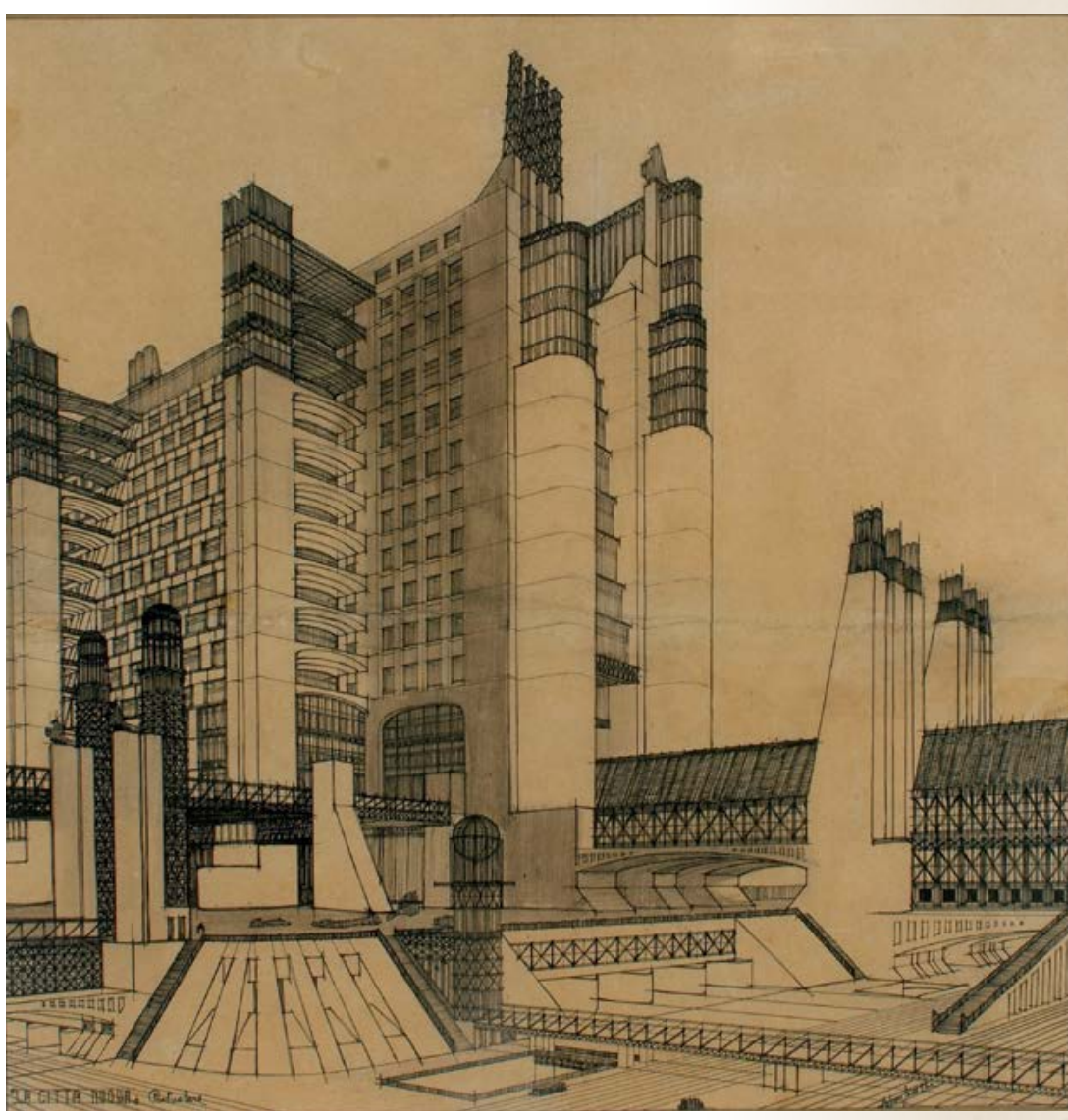

A Figura 3. Casa Sant'Elia, con ascensor externo y sistema de conexiones a diferentes niveles de calle Fuente: SantÉlia (1914). Dominio público.

podía llevarse a cabo bajo la lucha y mediante una forma de violencia (p. 22).

La destrucción y devastación que produjo el conflicto liquidó vidas, arrasó ciudades y desapareció naciones, pero también lapidó símbolos, aniquiló instituciones y eliminó entidades que representaban el yugo y la opresión. La catástrofe era, ciertamente, un acto manumisor, purificador y catártico con el que, tras la negación de lo ocurrido, el escenario quedaba impoluto y desnudo, visionando el paraíso donde concebir la utopía modernizante en la línea de progreso que direccionaba una humanidad unificada, bajo el principio de razón universal, a la creación de una naturaleza artificial de orden absoluto y frente a la cual Hans Jaffé, al recordar el manifiesto fundacional de De Stijl (citado por Subirats, 1986), apunta que "los artistas actuales de todo el mundo, impulsados por una y la misma conciencia, han participado en la esfera espiritual de la guerra mundial contra el predominio del individualismo".

Fue así como las nuevas experiencias artísticas tendrían en sus manos las herramientas para borrar de tajo el mundo precedente y sustituirlo por uno completamente nuevo. La imagen idealizada surgiría de la naciente industrialización y del apego del proyectista a la misma, con lo que, en 


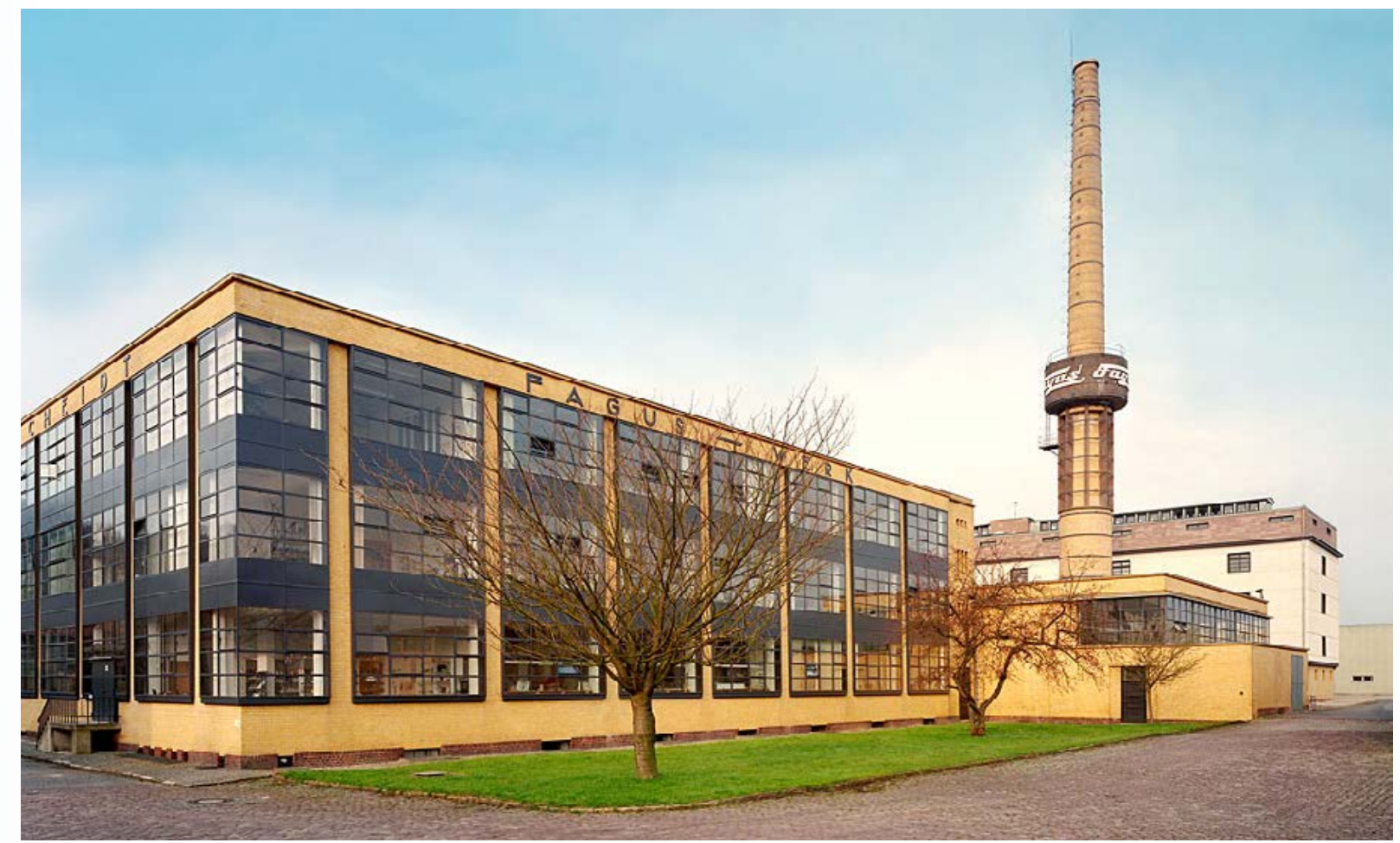

A Figura 4. Fábrica Fagus en Alfeld (1913), Walter Gropius, Alemania

Fuente: Janssen (2007). CC BY-SA voz de Giedion (1978), sería el momento en que la mecanización se hizo del dominio universal.

La postura teórica de Giedion acompañó a las vanguardias a través de diferentes textos alentando el espíritu emancipatorio de las mismas, y dio a su vez a la arquitectura moderna la distancia suficiente del diseño como disciplina hasta el momento en que su rumbo fue independiente de los demás saberes próximos y profesiones para, finalmente, ver años más tarde su rol de adalid con el cual guiaría una segunda oleada de movimientos producto de la eterna juventud de las vanguardias, para algunos, o del fin de las mismas o de su agonía, para otros. Este asunto, en el mejor de los casos, fue la ablación del recién superado pasado y, medianamente, el olvido de quienes habían migrado a América y hallaron en él su brújula, pues Europa yacía en ruinas y ya no era Occidente el modelo, era Norteamérica el mesías que, en la segunda mitad del siglo XX, había desplazado el Jardín del Edén, varios miles de kilómetros al oeste.

Es necesario, entonces, reconocer como lo hace Aicher (1994, p. 40) - aunque en su caso con intención de señalarlas con cierto descrédito como la "tercera modernidad" —, que las primeras revelaciones de cambio tuvieron su ejemplificación en lo que podría ser la celebración de los desarrollos tecnoindustriales derivados de la mecanización devenida de la Revolución Industrial, en monumentales estructuras de acero y vidrio, como el Crystal Palace de Joseph Paxton construido en Londres para la Gran Exhibición de los Trabajos de la Industria de Todas las Naciones en 1851, y seguidamente la Torre Eiffel para la Exhibición Universal de París en 1889, es decir, grandilocuentes edificaciones que hablarían de la estrepitosa caída del mundo antiguo y del surgimiento de uno nuevo que, aunque con referencias al periodo donde se socava y demuele lo añejo y rancio para edificar una cultura colosal, sería ingenuo ignorar que este momento perteneció al siglo XIX.

La arquitectura sería portadora de la imagen simbólica de transformación del diseño que los primeros manifiestos elaborarían en lenguajes apodícticos de avanzada al futuro y de resistencia al pasado en sentido marcial. Sin embargo, con ejemplos como los citados líneas arriba, la lucha interna con la anacrónica y vetusta efigie de una antigüedad que se quería vencer, aún era una ardua tarea por cumplir. El asunto, sin duda, nos remite a la noción de cambio contingente que la imagen desarrolla en la cultura, como señala José Luis Brea (2005), y que en la primera noción de imagen, la misma que él denomina imagenmateria, se configura en la retención del tiempo, de la memoria, en la idea encarnada que permite mantenerse estacionario en una dimensión temporal puntual y a la que se puede acudir con solo regresar la mirada a ella, dejándola inmutable. Es que lapidar el pasado no es tan sencillo y no todos están dispuestos a ser verdugos.

En este caso habría que reconocer los desarroIlos que la Revolución Industrial había engendrado, materializados en los magnánimos armazones de hierro y vidrio que, como umbrales, permitían el ingreso triunfante de la anhelada Modernidad. 
Sin embargo, esta febril rebelde sutilmente entró en sociedad en los estertores del siglo XIX, vistiendo su "piel" con la iconografía de las formas clásicas en un intento por extraer de las postrimerías lo que consideraba excelso en una estética tardía, lo cual es, en el juicio más moderado, una consideración aún romántica y ciertamente temerosa de alzar la espada de Damocles para decapitar de tajo el pasado.

Valga señalar que en los inicios del siglo XX la búsqueda por el edificio total (Figura 4), que defenderían las escuelas alemanas con mayor ahínco, para aquel momento parecería incomodarse tanto con su vestidura que, de pronto, el edificio comenzó a desbordar su interior espiritualizado a través de las frágiles osaturas sobre las pieles acristaladas, revelando la armadura que permitía que la estructura se elevara hasta los cielos como, paradójicamente, siglos antes lo habría hecho, en aquella ocasión en piedra y en manos de dedicados artesanos, la catedral gótica.

El templo medieval consumaba los anhelos del pueblo unificado bajo el amparo del Dios redentor que recibía por igual a sus hijos para resguardarlos el calor de sus fanales y bajo el cobijo de su manto, de las perversidades del mundo malevo que por fuera les acechaba. Es así como la nueva catedral refleja la máxima de los pioneros modernos cuando aseveraban que, parafraseando a Morris, no querían arte para unos pocos, como no querían educación para unos pocos, ni libertad para unos pocos, diríamos nosotros, ni mundo para unos pocos; ahora el mundo era un anhelo que habría de consumarse para todos (Pevsner, 2003).

Emprender la mesiánica labor de reivindicarse, humanamente hablando, y a partir de la carencia, a través del trabajo común y la lucha libertaria materializada en la imagen de la catedral, por ser ella el templo de la salvación, el edificio único, total, de inconfundible función práctica y espiritual, instituido por una operación colectiva unida tras un propósito social sublime, era hablar, en el siglo XX, por y para el mundo. Bien decía Mies en la Revista $G$

Las catedrales medievales tienen importancia para nosotros como creaciones de toda una época, no como obras de arquitectos individuales [...] son expresiones puras de su tiempo. Su verdadero significado reside en que son símbolos de su época, [de manera que] nuestros edificios utilitarios solo podrán llegar a ser dignos del nombre de arquitectura si interpretan verdaderamente su época mediante una expresión funcional perfecta (citado por Banham, 1985, p. 275).

El supuesto que estamos poniendo en consideración del lector es que el nacimiento del diseño en pleno inicio del siglo XX parte desde la ya mencionada "ausencia", la ablación del pasado, con una particular relación atávica con la imagen espiritualizada de la catedral que, como un vehículo de exposición, parece revelarse en la concepción de estas estructuras de la primera Modernidad dejando entrever los ecos, significativamente tardíos en este caso, de la configuración de la imagen para la era de la logosfera que ha sido definida magistralmente por Regis Debray (2010), quien señala que en dicho proceso se activa la relación de poder en doble vía al rendir tributo y recibir salvación, "lo divino hace bajar los ojos, lo sagrado hace levantar la cabeza" (p. 55), y frente a ello nada podría superar la materialidad sublimada de la casa del Dios cristiano, del dios de Occidente, del dios europeo, es decir, nada podría remontar a la gloriosa Europa, la misma que, paradójicamente y a hurtadilas, gestaba su inminente autodestrucción.

El plan era la imagen redentora que, en clave de utopía, conduciría a la salvación, de manera similar a como lo habían hecho las esbeltas caterales flamíneas que se desmaterializaban desvaneciendo su fiscicidad a medida que ganaban altura. En manos del proyectista estaba la elevación de los ojos de la masa, no ante la esbeltez de sus edificios, sino ante la magnanimidad de su creación visionaria, una que señalaba el camino a un mundo mejor.

Mientras se adentraba el primer tercio del siglo XX, el "edificio total", desde el esqueleto hasta la piel, fue cediendo la supremacía de su imagen celestial constitutiva de lo simbólico, pues aunque en ella residía gran parte de la esperanza de la existencia de la vida, una vida que surgía como fuente de luz desde el interior mismo creación del menestral hasta la dicotomía por el lastre del pasado y la labor artesanal dicha expresión magnánime fue pasando su cuenta de cobro a las aguerridas vanguardias solícitas de dejar la historia atrás.

Queda claro que el cimiento sobre el cual se había edificado el movimiento moderno, en su más amplia acepción, mantendría por varios años el halo poético y espiritual que distinguiría la ten- 
dencia expresionista de los productos humanos de las artes de aquel entonces. Sin embargo, al adentrarse la década de los treinta, el quehacer diseñístico debió asir la noción kantiana de arte como habilidad humana, posibilidad de obrar o facere en voz de la crítica de la facultad de juzgar kantiana (Kant, 1991), desprendiéndose paulatinamente de la mano del artesano y aferrándose a la máquina con el ánimo de dar respuesta a la capacidad de producir objetos normalizados y estandarizados que cubrieran las necesidades de todas las esferas económicas y sociales, sumado al derecho legítimo del hombre común de acceder a productos ideales proyectados por sujetos versados en la disciplina, y no por seres anónimos, hijos de la anquilosada historia y la tradición (Oyarzún, 1983, pp. 246), el asunto es que la realidad, finalmente, parecía superar gloriosa a la quimera.

El asunto ontológico que en el fondo se configuraba gozaba de dos aspectos de gran significación. El primero tenía que ver con la noción de hacer u obrar frente a la cual, valiéndonos nuevamente de los idealistas, refería al direccionamiento de una praxis cobijada por el carácter intelectual del acto creativo, entiéndase a la producción por libertad, es decir, a través de una voluntad que pone la razón a la base de sus acciones (Kant, 1991) y, la segunda, que ligaba los productos humanos derivados del actuar soberano y consciente con su capacidad futura de ser, es decir, la vinculación de la noción cientificista de racionalidad estética que subyacía en el manifiesto, en el modelo o en

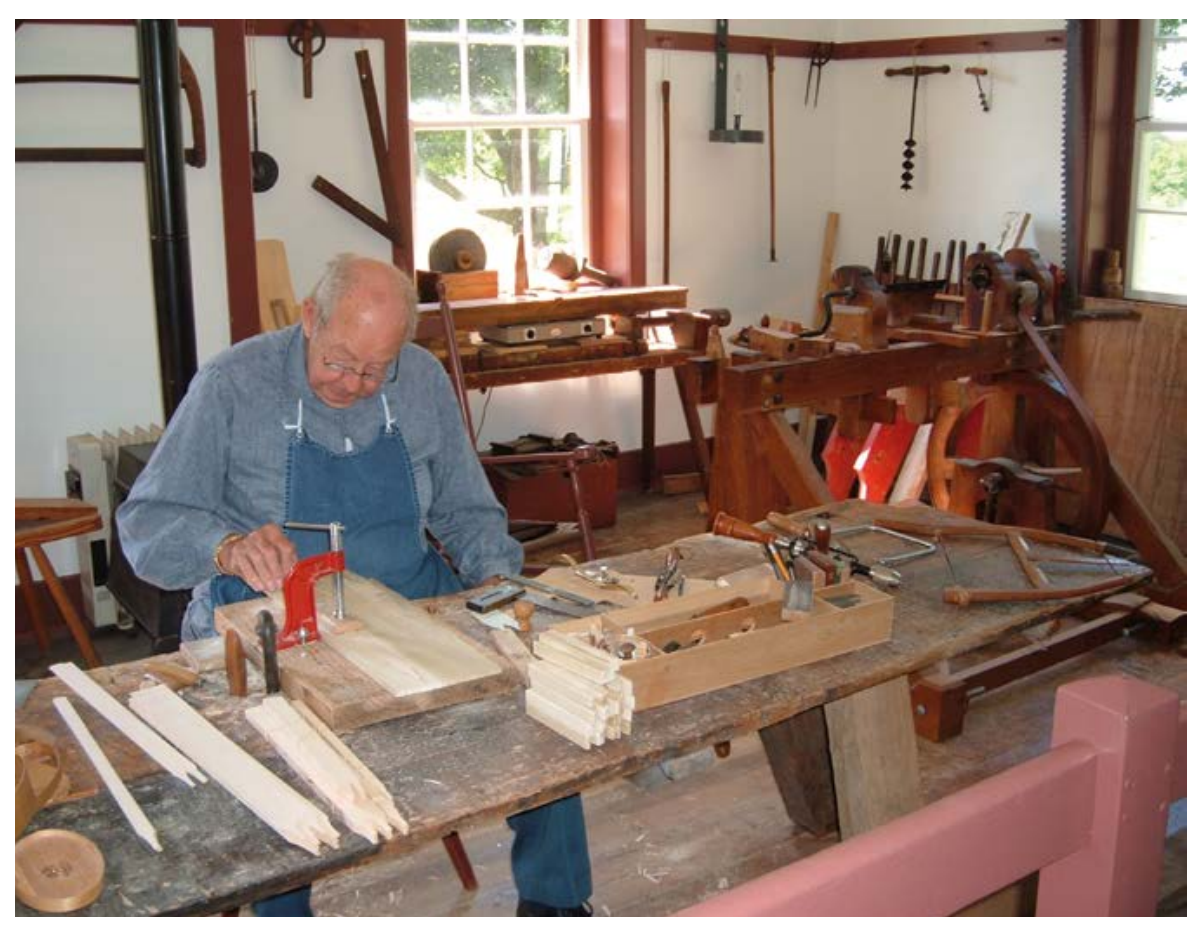

el arquetipo; en suma, el "plan" académicamente concebido, con la consideración constructiva o la afirmación material que anunciaba que los mismos estaban cargados de la potencia de lo que en un mundo posible y artificializado habrían de ser. Si la preocupación orbitaba alrededor de la condición misma de los objetos resultado de la acción beligerante, ¿qué decir del hombre sublevado, promotor y motor de la revolución? Se hace necesario ahora, entonces, dar cuenta de la mano que hace, del genio creador, del diseñador y proyectista.

Como señalábamos en el comienzo del presente texto, para Platón el obrador, cuya labor ilustra sabiamente a través del ejemplo de las "tres camas", es el sujeto capaz de fabricar la particularización material de lo que por naturaleza no puede sino ser único en esencia y ha sido creado por dios, quien jamás cambiaría su tarea de autor por la de fabricante, pues esta es una función eminentemente humana. Según Platón (1994),

Hay tres clases de camas; una, que está en la naturaleza y cuyo autor podemos, a mi parecer, decir que es el dios. [...]

La segunda es la que hace el carpintero. [...]

Y la tercera, la que es obra del pintor; ¿no es así?

[...] Respecto del dios, ya lo haya querido o ya haya sido una necesidad para él el hacer una sola cama esencial, el resultado es que no ha hecho más que una, que es la cama propiamente dicha.

[...] ¿Daremos al dios el título de productor de la cama u otro semejante? ¿Qué crees tú?

Ese título le pertenece, ha hecho por sí mismo la esencia de la cama y la de todas las demás cosas.

Y al carpintero ¿cómo le llamaremos? El obrador de la cama, sin duda.

Respecto del pintor ¿diremos que es obrador o el productor?

De ninguna manera.

[...] El único nombre, que razonablemente se le puede dar, es el de imitador de la cosa, respecto de la que los otros son operarios.

[...] El arte de imitar está, por consiguiente, muy distante de lo verdadero, y si ejecuta tantas cosas es porque no toma sino una pequeña parte de cada una; y aun esta pequeña parte no es más que un fantasma. El pintor, por ejemplo, nos representará a un zapatero, a un carpintero o a cualquiera otro artesano, sin conocer nada estos oficios. A pesar de esto, si es un excelente pintor, alucinará a los niños y al vulgo ignorante, mostrándoles de lejos al carpintero que haya pintado, de suerte que tomará la imitación por la verdad (pp. 349-351). 
La mano artesana del obrero que fabrica los objetos particulares apenas si logra estar próxima a la verdad y su cercanía está mediada por dos aspectos. Uno, su pretensión de dar cuenta de la esencia de las cosas creadas por dios y, dos, la búsqueda por la conveniencia al fin, es decir, el procurar la finalidad práctica en términos de uso; volviendo al ejemplo de la cama, esta puede ser reconocida y usada como cama, indistintamente de la cultura de donde el hombre provenga, de la religión que practique, de su filiación política o de la lengua en que se comunique, solo por citar algunos ejemplos.

Si bien es cierto que la discusión de la finalidad práctica, el uso o la función social y política pueden y deben abrir un amplio espacio en una honda discusión sobre el diseño, por el momento nos interesa resaltar que ese carpintero, el artesano que produce la cama, el operario de la naturaleza del ser obrador, era visto como un sujeto de calidades excepcionales que en su tarea diseñística daba cuenta de dos procesos simultáneos (Figura 5). El primero, reconocía que en su actividad residía la labor más cercana a la del demiurgo, en tanto la elaboración de una pieza artesanal manual solo puede producir objetos irrepetibles, pues por más que el modelo sea elaborado una y otra vez, su proceso de producción lo hace único. El segundo, evidenciaría la simultaneidad del proyectar y el materializar lo imaginado. Es justo ahí, en ese proceso, donde se logra construir conocimiento "a través" de la praxis del diseño, como advierte Sevaldson (2010) al poner en perspectiva el panorama de la discusión alrededor de la manera de investigar asuntos del diseño y las corrientes de pensamiento que las impulsan actualmente.

En relación con primer proceso que considera el advenimiento de la Modernidad determinado por la singularidad, recordemos la imagen del edificio total encumbrado en la nueva catedral, que surgía de la labor del artesano poseedor de un talento innato cuya habilidad prolija se manifiestaba en la configuración de modelos que, posteriormente estereotipados, servirían a la ulterior reproducción. Sin reiterar las miserias de la imitación o entrar a discutir "la pérdida del aura" que tanto angustiaba a Benjamin (1973), habríamos de reconocer que en la originalidad y la ejemplaridad residían los elementos que habrían de legitimar la estética que normalizaría, no solo la belleza de los objetos creados (Kant, 1991), sino, también, portarían del mensaje emancipatorio que las vanguardias rigurosamente habían trazado en sus manifiestos fundacionales, es decir, la correspondencia con la función social del diseño, su ethos, el deber sociopolítico de quienes harían posible que el hombre común soñara con lo que antes solo le pertenecía a las élites de la sociedad. Era la apertura a un nuevo mundo, a una sociedad aparentemente libre e igualitaria, y la llave para abrir la puerta estaba en la mano del genio creador, hijo de la Modernidad.

El panegírico de la labor manual fue un acto de fe y esperanza en el genio que encumbraba con los productos de la cultura la idea teleológica de creación absoluta, al recoger en el gran relato modernizante la utopía, el sueño, la quimera de un único mundo posible erigido a voluntad humana. Este artista posee lo que Kant (1991) denomina el genio o

...el talento (don natural), que le da la regla al arte. Dado que el talento, como facultad productiva innata del artista, pertenece, él mismo, a la naturaleza, podría uno entonces expresarse también así: genio es la innata disposición del ánimo (ingenium) a través de la cual la naturaleza le da la regla al arte (pp. 252).

Una buena parte de la comunidad artística encaminaría su actividad en la ruta trazada por la línea de progreso que solo conocía la meta certera de reconciliación consigo mismo u "odisea del espíritu" hegeliana. La prevalencia de los productos de la cultura a través de la humanización de la técnica era una manera de enaltecer moralmente el andar, pues la ardua tarea que emprendía diariamente el artesano - cuya labor salva la distancia entre la magia que residía en la iconografía del pasado más antiguo cuyos objetos son pagamentos que se alejan de los mortales para encumbrarse en los cielos y acercarse a los dioses desmaterializándose para ser, metafóricamente hablando, espíritu puro- permitía que el arte se acercara a la imagen pura tan pronto el embrujo se retiraba de ella posibilitando que el objeto imaginado y simultáneamente fabricado diera cuenta de un mejor mundo vivido. Al menos esa era la ilusión y, como toda fantasía, terminó por desvanecerse en el aire. Lo interesante del asunto es que era una utopía humana, un proyecto de la voluntad mortal, y por primera vez no era un llamado del dios a los hombres, no era un designio divino. 
Si bien es cierto que aunque el humanismo parecía estar de nuevo en boga, humanizar todo, particularmente la técnica, es un tema que tampoco podría sostenerse por mucho tiempo y bastarían solo unos pocos años para que la presión del mundo maquinizado, la imposibilidad de legitimar las sublimaciones extáticas y el apremio del ethos revolucionario-político, ligado a las manifestaciones artísticas, derivaran en la ruptura total.

El siglo XX terminó su segunda década con el final de una guerra desoladora que muchos defendieron por ser la "redención necesaria" frente a la decadencia cultural y artística del siglo XIX; la mesiánica revolución que apenas si advertía la debacle que sería la Segunda Guerra Mundial, que iniciaría menos de veinte años después. La verdad es que cambiar era un imperativo categórico que ya no se podía evadir más. Bien señalaría Aicher:

...El diseño [...] es un invento del siglo XX, nacido
paralelamente a la producción industrial. [... Era]
un movimiento cultural cuya meta era superar la
clásica cultura de la burguesía, fijada en estilos
históricos. Tiene hasta hoy no solo una dimen-
sión económica sino también cultural. Si antaño
la pregunta de la cultura era cómo, en tanto que
ser humano, podía uno instalarse en una reali-
dad configurada por la naturaleza y en un mundo
dado, ahora, frente al mundo de mercancías
producidas industrialmente, se plantea la pre-
gunta de cómo un ser humano puede estable-
cerse, y quizá también afirmarse y defenderse,
en un nuevo mundo hecho de artefactos técnicos
(2001, p. 131).

Tomar la decisión de desprenderse de la mano del artesano en su labor de labrar, para asirse de la idea de la mano que ase la palanca que, a su vez, insufla movimiento a la máquina, era el anuncio de lo que habría de venir en las artes, proyectar y producir eran procesos independientes, la época de la humanización de la técnica por la vía de la reconciliación del arte había pasado, y ahora el proceso productivo, industrializado, analítico, divisible, independiente rompería lazos con la tradición, caracterizando el diseño hasta nuestros días. No obstante, cuando se abre la reflexión hacia la dimensión humana que hoy declara el diseño, la "tercer área del saber", ¿qué hacer con el germen mesiánico, la idea desarrollista del diseño, la ablación del pasado, el "plan" como margen de la utopía?, ¿qué hacer con la búsqueda interminable por alcanzar la redención, si en el escenario parece instalarse el hacedor, el obrador sin formación como proyectista y gran productor del mundo?, ¿qué hacer con este proyectar?

\section{Conclusiones}

Si bien la mano puede ser entrenada en un grado de facilidad automática, una facultad le es negada: permanecer invariantemente activa. Siempre debe estar agarrando, sosteniendo, manipulando. No puede continuar un movimiento de rotación sin fin. Eso es precisamente lo que implica la mecanización: interminable rotación. La diferencia entre caminar y rodar, entre piernas y rueda es básica para toda la mecanización, según defendía Giedion (1978); también la mano puede estar concebida para pensar — valga acudir a Juhani Pallasmaa-, para dar tránsito a las formas de comprender el mundo apropiado e incorporado, una manera otra de pensar las lógicas actuales del proyecto.

Era claro que con la mecanización no solo habría división y transformación del trabajo, sino que sobrevendría una evidente distinción entre la labor artesanal/manual y la seriada/maquínica; sería el surgimiento de la autonomía disciplinar del diseño y, por qué no señalarlo en este momento, de las más radicales posturas que podrían distinguir las utopías de las heterotopías hasta abrir, también, el camino al "mundo como proyecto", un mundo que se cocía lentamente al fuego de la guerra.

No pasarían muchos años para que la debacle de la guerra ratificara los grandes temores de Giedion sobre la naturaleza que subyacía en la mecanización de la vida, y era que esta no necesariamente implicaba progreso, con lo cual el argumento hegeliano parecía perder brillo. Haber logrado desarrollar la energía atómica derivó en la destrucción masiva, la industria metalmecánica produjo armamento a unas proporciones que faltaría humanidad para combatir con ellas, la industria química no solo produjo medicamentos, sino que se dedicó a experimentar con el hombre jugando a ser dioses.

Desarrollar la ciencia no necesariamente implicaba tener los logros en el campo de aplicación que el proyectista deseaba a beneficio de la humanidad, al menos no en el sentido amplio, sino que podía, también, beneficiar fragmentos sociales en el aspecto mercantilista, de poder, económico, pero no siempre en el ético. El epílogo del libro de Giedion es, tal vez, el apartado 
más interesante de todo el texto en tanto parece poner nuevamente sobre la mesa el ethos de la Modernidad mecanizada y, en consecuencia, el deber ser de la disciplina diseñística que puede no tener el "plan" como fin, sino el bienestar humano como proyecto. Dice:

Nunca ha poseído la humanidad tantos instrumentos para abolir la esclavitud, pero las promesas de una vida mejor no han sido mantenidas. Cuanto podemos mostrar hasta hoy es una incapacidad muy inquietante en cuanto a organizar el mundo, e incluso para organizarnos a nosotros mismos. Es posible que las generaciones futuras designen a este periodo como una época de barbarie mecanizada, que es la más repulsiva de todas las barbaries (1978, p. 714).

Es justo aquí cuando surge el momento de inflexión al que hicimos referencia al comenzar nuestra reflexión, es decir, la oportunidad de pensar el diseño como una disciplina que, al haber surgido necesariamente de la revolución mesiánica que dispuso su anhelo en la utopía modernizante — pues a pesar de las múltiples críticas y señalamientos que se le han hecho y aún se le hacen, creemos importante no perder de vista que en ella subyacía la lucha por un mejor mundo humano y eso es más que suficiente para darle legitimidad histórica y cultural-, sin embargo, es cierto que lo que de ella emanó no logró sostenerse como meta y perdió sentido en su búsqueda teleológica, razón de más para creer que este quehacer amerita ser repensado y reinterpretado como proyecto en el escenario, ya no de las utopías maquinizadas, sino en el de las realidades humanizadas, por llamarlo de alguna manera, ya sea como disciplina autónoma, como hacer, como saber y ciencia comprometidos con una visión antropologizada de la praxis proyectual actual.

\section{Referencias}

Aicher, O. (2001). Analógico y digital. Barcelona: Gustavo Gili.

Aicher, O. (1994). El mundo como proyecto. México: Gustavo Gili.

Allen, T. (2005). Archivo: Shakertown Craftsman Boxes [Fotografía]. Recuperado de https:// es.m.wikipedia.org/wiki/Archivo:Shakertown Craftsman_Boxes_2005-05-27.jpeg

Archer, B. (1979). Design as a discipline. Design Studies, 1 (1), 17-20. Recuperado de http:// dx.doi.org/10.1016/0142-694X(79)90023-1

Archer, B. (1995). The nature of research. Codesign, Interdisciplinary Journal of Design, 1 (1), 6-13.

Banham, R. (1985). Teoría y diseño en la primera era de la máquina. Barcelona: Paidós.

Benjamin, W. (1973). La obra de arte en la época de su reproductibilidad técnica. Madrid: Taurus.

Brea, J. L. (2005). Estudios visuales. La epistemología de la visualidad en la era de la globalización. Madrid: Akal.

Buchanan, R. (1998). Education and professional practice in design. Design Issues, 14 (2), 63-66.

Buchanan, R. (2001). Design research and the new learning. Design issues, 17 (4), 3-23.

Cross, N. (1982). Designerly ways of knowing. Design studies, 3 (4), 221-227.

Cross, N. (2011). Design thinking: Understanding how designers think and work. Oxford: Berg.

Debray, R. (2010). Vida y muerte de la imagen. Historia de la mirada en Occidente. Barcelona: Paidós.

Forlizzi, J., Zimmerman, J. y Stolterman, E. (2009). From design research to theory: Evidence of a maturing field. International Association of Societies of Design Research Conference.
Foucault, M. (1966/2010). El cuerpo utópico. Las heterotopías. Buenos Aires: Nueva Visión.

García Canclini, N. (2001). Culturas híbridas. Estrategias para entrar y salir de la modernidad. Buenos Aires: Paidós.

Giedion, S. (1948/1978). La mecanización toma el mundo. Barcelona: Gustavo Gili.

Hegel, G. (2010). La odisea del espíritu. Madrid: Círculo de Bellas Artes de Madrid.

Hernández, F. (2006). Campos, temas y metodologías para la investigación relacionada con las artes. En Gómez, M., Hernández, F. y Pérez, H. C. Bases para un debate sobre investigación artísitca (pp. 681-713). Madrid: Ministerio de Educación y Ciencia.

Hobsbawm, E. (1998). Historia del siglo XX. Buenos Aires: Crítica.

Janssen, C. (2007). Das Fagus-Werk in Alfeld, Rückseite [Fotografía]. Recuperado de https:// commons.wikimedia.org/wiki/File:Fagus Gropius_Hauptgebaeude_200705_wiki rueckseite.jpg

Kant, E. (1790/1991). Crítica de la facultad de juzgar. Caracas: Monte Ávila Editores.

Manzini, E. (2009). New design knowledge. Design Studies, 30 (1), 4-12. http://dx.doi. org/10.1016/j.destud.2008.10.001

Marinetti, F. T. (1909/2006). Critical Writings. New York: Farrar, Straus and Giroux.

Montaner, J. M. (1997). La Modernidad superada: ensayos sobre arquitectura contemporánea. Barcelona: Gustavo Gili.

National Archives and Records Administration (1943). Women's Bureau [Fotografía]. Recuperado de https://es.wikipedia. org/wiki/Archivo:\%22 Line up of some of women welders including the women $\% \overline{2} 7$ s_welding_champion_of Ingalls_(Shipbuilding_Corp.,_Pascagoula,_MS $)_{-}$NARA_-_522890.jpg
Oyarzun, P. (ed.) (1983). Textos estéticos: Immanuel Kant. Santiago de Chile: Andrés Bello.

Pallasmaa, J. (2012). La mano que piensa. Sabiduría existencial y corporal en la arquitectura. Barcelona: Gustavo Gili.

Pevsner, N. (2003). Pioneros del diseño moderno. Buenos Aires: E. I. SRL.

Platón (1994). La República o el Estado. Madrid: Ediciones Fontana.

SantÉlia (1914). Casa con ascensori esterni e sistemi di collegamento su più piani stradali [Fotografía]. Recuperado de https:// es.wikipedia.org/wiki/Archivo:Casa_ Sant'Elia.jpg

Saikaly, F. (2005, March). Approaches to design research: Towards the designerly way. En Sixth international conference of the European Academy of Design (EAD06). Bremen: University of the Arts. Recuperado de: http://ead.verhaag.net/fullpapers/ead06_ id187_2.pdf

Sevaldson, B. (2010). Discussions and movements in design research. FORMakademisk - Research Journal for Design and Design Education, 3 (1), 8-35. Recuperado de http: //dx.doi.org/10.7577/formakademisk.137

SiefkkinDR (2016). Model of the Plan Voisin for Paris by Le Corbusier displayed at the Nouveau Esprit Pavilion (1925) [Fotografía]. Recuperado de https://commons.wikimedia.org/wiki/File:Plan_Voisin_model.jpg

Subirats, E. (1986). La flor y el cristal. Barcelona: Anthropos. 
La postulación de un artículo a la Revista de Arquitectura indica que- el o los autores certifican que conocen y aceptan la política editorial, para lo cual firmarán en original y remitirán el formato RevArq FP00 Carta de originalidad.

La Revista de Arquitectura maneja una política de Autoarchivo VERDE, según las directrices de SHERPA/RoMEO, por lo cual el autor puede:

- Pre-print del autor: Archivar la versión pre-print (la versión previa a la revisión por pares)

- Post-print del autor: Archivar la versión post-print (la versión final posterior a la revisión por pares

- Versión de editor/PDF: Archivar la versión del editor - PDF/HTML/XLM en la maqueta de la Revista de Arquitectura.

El Autoarchivo se debe hacer respetando la licencia de acceso abierto, la integridad y la imagen de la Revista de Arquitectura, también se recomienda incluir la referencia, el vínculo electrónico y el DOI.

El autor o los autores son los titulares del Copyright (c) del texto publicado y la Editorial de la Revista de Arquitectura solicita la firma de una autorización de reproducción del artículo (RevArq FP03 Autorización reproducción), la cual se acoge a la licencia CC, donde se expresa el derecho de primera publicación de la obra.

La Revista de Arquitectura se guía por las normas internacionales sobre propiedad intelectual y derechos de autor, y de manera particular el artículo 58 de la Constitución Política de Colombia, la Ley 23 de 1982 y el Acuerdo 172 del 30 de septiembre de 2010 (Reglamento de propiedad intelectual de la Universidad Católica de Colombia).

Para efectos de autoría y coautoría de artículos se diferencian dos tipos: "obra en colaboración" y "obra colectiva". La primera es aquella cuya autoría corresponde a todos los participantes al ser fruto de su trabajo conjunto. En este caso, quien actúa como responsable y persona de contacto debe asegurar que quienes firman como autores han revisado y aprobado la versión final, y dan consentimiento para su divulgación. La obra colectiva es aquella en la que, aunque participan diversos colaboradores, hay un autor que toma la iniciativa, la coordinación y realización de dicha obra. En estos casos, la autoría corresponderá a dicha persona (salvo pacto en contrario) y será suficiente únicamente con su autorización de divulgación.

El número de autores por artículo debe estar justificado por el tema, la complejidad y la extensión, y no deberá ser superior a la media de la disciplina, por lo cual se recomienda que no sea mayor de cinco. El orden en que se enuncien corresponderá a los aportes de cada uno a la construcción del texto, se debe evitar la autoría ficticia o regalada. Si se incluyen más personas que trabajaron en la investigación se sugiere que sea en calidad de colaboradores o como parte de los agradecimientos. La Revista de Arquitectura respetará el número y el orden en que figuren en el original remitido. Si los autores consideran necesario, al final del artículo pueden incluir una breve descripción de los aportes individuales de cada uno de firmantes.

La comunicación se establece con uno de los autores, quien a su vez será el responsable de informar a los demás autores de las notificaciones emitidas por la Revista de Arquitectura.

En virtud de mantener el equilibro de las secciones y las mismas oportunidades para todos los participantes, un mismo autor puede postular dos o más artículos de manera simultánea; si la decisión editorial es favorable y los artículos son aceptados, su publicación se realizará en números diferentes.

\section{A Acceso abierto}

La Revista de Arquitectura, en su misión de divulgar la investigación y apoyar el conocimiento y la discusión en los campos de interés, proporciona acceso abierto, inmediato e irrestricto a su contenido de manera gratuita mediante la distribución de ejemplares impresos y digitales. Los interesados pueden leer, descargar, guardar, copiar y distribuir, imprimir, usar, buscar o referenciar e texto completo o parcial de los artículos o la totalidad de la Revista de Arquitectura.

\section{(c) (1) (3)}

Esta revista se acoge a la licencia Creative Commons (CC BYNC de Atribución - No comercial 4.0 Internacional): "Esta licencia permite a otros entremezclar, ajustar y construir a partir de su obra con fines no comerciales, y aunque en sus nuevas creaciones deban reconocerle su autoría y no puedan ser utilizadas de manera comercial, no tienen que estar bajo una licencia con los mismos términos".

La Revista de Arquitectura es divulgada en centros y grupos de investigación, en bibliotecas y universidades, y en las principales facultades de Arquitectura, mediante acceso abierto a la versión digital y suscripción anual al ejemplar impreso o por medio de canje, este último se formaliza mediante el formato RevArq FP20 Canjes.

Para aumentar su visibilidad y el impacto de los artículos, se envían a bases de datos y sistemas de indexación y resumen (SIR) y, asimismo, pueden ser consultados y descargados en la página web de la revista.

La Revista de Arquitectura no maneja cobros, tarifas o tasas de publicación de artículo (Article Processing Charge-APC), o por el sometimiento de textos a la publicación.

\section{(1)Ética y buenas prácticas}

La Revista de Arquitectura se compromete a cumplir y respetar las normas éticas en todas las etapas del proceso de publicación. Los autores de los artículos publicados darán cumplimiento a los principios éticos contenidos en las diferentes declaraciones y legislaciones sobre propiedad intelectual y derechos de autor específicos del país donde se realizó la investigación. En consecuencia, los autores de los artículos postulados y aceptados para publicar, que presentan resultados de investigación, deben firmar la declaración de originalidad (formato RevArq FP00 Carta de originalidad).

La Revista de Arquitectura reconoce y adopta los principios de transparencia y buenas prácticas descritos por COPE, "Principles of Transparency and Best Practice in Scholarly Publishing" (2015).

El equipo editorial tiene la obligación de guardar la confidencialidad acerca de los artículos recibidos, y abstenerse de usar en sus propias investigaciones datos, argumentos o interpretaciones hasta tanto el artículo no sea publicado. También debe ser imparcial y gestionar los artículos de manera adecuada y en los plazos establecidos. La selección de revisores se hará con objetividad y estos deberán responder a la temática del artículo.

El editor, los autores y los revisores deben seguir las normas éticas internacionales definidas por el Committee on Publication Ethics (COPE), con el fin de evitar casos de:

- Fabricación, falsificación u omisión de datos.

- Plagio y autoplagio.

- Publicación redundante, duplicada o fragmentada.

- Omisión de referencias a las fuentes consultadas.

- Utilización de contenidos sin permiso o sin justificación.

- Apropiación individual de autoría colectiva.

- Cambios de autoría.

- Conflicto de interés (CDI) no revelado o declarado.

- Otras que pudieran surgir en el proceso de investigación y publicación. La fabricación de resultados se genera al mostrar datos inventados por los autores; la falsificación resulta cuando los datos son manipulados y cambiados a capricho de los autores; la omisión se origina cuando los autores ocultan deliberadamente un hecho o dato. El plagio se da cuando un autor presenta como ideas propias datos creados por otros. Los casos de plagio son los siguientes: copia directa de un texto sin entrecomillar o citar la fuente, modificación de algunas palabras del texto, paráfrasis y falta de agradecimientos; el autoplagio se da cuando el mismo autor reutiliza material propio que ya fue publicado, pero sin indicar la referencia al trabajo anterior. La revista se apoya en herramientas digitales que detectan cualquiera de estos casos en los artículos postulados, y es labor de los editores y revisores velar por la originalidad y fidelidad en la citación. La publicación redundante o duplicada se refiere a la copia total, parcial o alterada de un trabajo ya publicado por el mismo autor

En caso de sospechar de alguna mala conducta se recomienda seguir los diagramas de flujo elaborados por COPE (2008), con el fin de determinar las acciones correspondientes.

La Revista de Arquitectura se reserva el derecho de retractación de publicación de aquellos artículos que, posterior a su publicación, se demuestre que presentan errores de buena fe, o cometieron fraudes o malas prácticas científicas. Esta decisión se apoyará en "Retraction Guidelines" (COPE, 2009). Si el error es menor, este se podrá rectificar mediante una nota editorial de corrección o una fe de erratas. Los autores también tienen la posibilidad de solicitar la retractación de publicación cuando descubran que su trabajo presenta errores graves. En todos los casos se conservará la versión electrónica y se harán las advertencias de forma clara e inequívoca.

\section{(A) Privacidad y manejo de la información.} Habeas Data

Para dar cumplimiento a lo previsto en el artículo 10 del Decreto 1377 de 2013, reglamentario de la Ley 1581 de 2012, y según el Acuerdo 002 del 4 de septiembre de 2013 de la Universidad Católica de Colombia, "por el cual se aprueba el manual de políticas de tratamiento de datos personales":

La Universidad Católica de Colombia, considerada como responsable o encargada del tratamiento de datos personales, manifiesta que los datos personales de los autores, integrantes de los comités y pares revisores, se encuentran incluidos en nuestras bases de datos; por lo anterior, y en cumplimiento de las disposiciones legales vigentes, la Universidad solicitará siempre su autorización, para que en desarrollo de sus funciones propias como Institución de Educación Superior, en especial las relacionadas con la docencia, la extensión y la investigación, la Universidad Católica de Colombia pueda recolectar, recaudar, almacenar, usar, circular, suprimir, procesar, intercambiar, compilar, dar tratamiento, actualizar, transmitir o transferir a terceros países y disponer de los datos que le han suministrado y que han sido incorporados en las bases de datos de todo tipo que reposan en la Universidad.

La Universidad Católica de Colombia queda autorizada, de manera expresa e inequívoca, en los términos señalados por el Decreto 1377 de 2013, para mantener y manejar la información de nuestros colaboradores (autores, integrantes de los diferentes comités y pares revisores); así mismo, los colaboradores podrán ejercer sus derechos a conocer, actualizar, rectificar y suprimir sus datos personales, para lo cual se han dispuesto las siguientes cuentas de correo electrónico: 
La Revista de Arquitectura recibe artículos de manera permanente. Los artículos se procesan a medida que se postulan, dependiendo el flujo editorial de cada sección.

El idioma principal es el español, y como opcionales están definidos el inglés, el portugués y el francés; los textos pueden ser escritos y presentados en cualquiera de estos.

Los artículos postulados deben corresponder a las categorías universalmente aceptadas como producto de investigación, ser originales e inéditos y sus contenidos responder a criterios de precisión, claridad y brevedad.

Como punto de referencia se pueden tomar las tipologías y definiciones del Índice Bibliográfico Nacional, Publindex (2010) que se describen la continuación:

1. Artículo de revisión: documento resultado de una investigación terminada donde se analizan, sistematizan e integran los resultados de investigaciones publicadas o no publicadas, sobre un campo en ciencia o tecnología, con el fin de dar cuenta de los avances y las tendencias de desarrollo. Se caracteriza por presentar una cuidadosa revisión bibliográfica de por lo menos 50 referencias.
2. Artículo de investigación científica y tecnológica: documento que presenta, de manera detallada, los resultados originales de proyectos terminados de investigación. La estructura generalmente utilizada contiene cuatro apartes importantes: introducción, metodología, resultados y conclusiones.

3. Artículo de reflexión: documento que presenta resultados de investigación terminada desde una perspectiva analítica, interpretativa o crítica del autor, sobre un tema específico, recurriendo a fuentes originales.

En todos los casos se debe presentar la información suficiente para que cualquier investigador pueda reproducir la investigación y confirmar o refutar las interpretaciones defendidas.

También se pueden presentar otro tipo de documentos diferentes a los anteriormente descritos, como pueden ser: artículo corto, reporte de caso, revisión de tema, documento resultado de la revisión crítica de la literatura sobre un tema en particular, cartas al editor, traducción, documento de reflexión no derivado de investigación, reseña bibliográfica, así como proyectos de arquitectura o urbanismo, entre otros

\section{A Instrucciones para postular artículos}

Postular el artículo en la página web de la Revista de Arquitectura y adjuntar comunicación escrita dirigida al editor RevArq_FP00 Carta de originalidad (debidamente firmada por todos los autores en original); de igual manera, se debe diligenciar el formato de hoja de vida RevArq FP01 Hoja de Vida (una por cada autor).

En la comunicación escrita el autor expresa que conoce y acepta la política editorial de la Revista de Arquitectura, que el artículo no está postulado para publicación simultáneamente en otras revistas u órganos editoriales y que no existe conflicto de intereses (ver modelo RevArq FP06 CDI) y que, de ser aceptado, concederá permiso de primera publicación, no exclusiva a nombre de la Universidad Católica de Colombia como editora de la revista.

Los artículos deben tener en cuenta las siguientes recomendaciones:

- En la primera página del documento se debe incluir:

Título: no exceder 15 palabras.

Subtítulo: opcional, complementa el título o indica las principales subdivisiones del texto.

Nombre del autor o autores: nombres y apellidos completos o según modelo de citación adoptado por el autor para la normalización de los nombres del investigador. Como nota al pie (máximo 150 palabras): formación académica, experiencia profesional e investigativa, vinculación laboral, código ORCID, premios o reconocimientos, publicaciones representativas e información de contacto, correo electrónico.

Filiación institucional: debajo del nombre se debe declarar la institución en la cual se desarrolló el producto, de la cual recibió apoyo o aquella que respalda el trabajo investigativo.

Resumen: debe ser analítico, se redacta en un solo párrafo, da cuenta del tema, el objetivo, la metodología, los resultados y las conclusiones; no debe exceder las 150 palabras.

Palabras clave: cinco palabras o grupo de palabras, ordenadas alfabéticamente y que no se encuentren en el título o subtítulo; estas sirven para clasificar temáticamente al artículo. Se recomienda emplear principalmente palabras definidas en el tesauro de la Unesco (http:// databases.unesco.org/thessp/), en el tesauro de Arte \& Arquitectura (C (www.aatespanol.cl), o Vitruvio (http://vocabularyserver.com/vitruvio/)

También se recomienda incluir título, resumen y palabras clave en segundo idioma.

\section{- La segunda página y siguientes deben tener en cuenta:}

El cuerpo del artículo generalmente se divide en: Introducción, Metodología, Desarrollo, Resultados y Discusión de resultados; posteriormente se presentan las Conclusiones, y luego las Referencias bibliográficas y los Anexos (método IMRYD). Las tablas y figuras se deben incorporar en el texto.

Descripción del proyecto de investigación: en la introducción se debe describir el tipo de artículo y brevemente el marco investigativo del cual es resultado y diligenciar el formato (RevArq FP02 Info Proyectos de Investigación).

TEXTO: todas las páginas deben venir numeradas y con el título de artículo en la parte superior de la página. Márgenes de $3 \mathrm{~cm}$ por todos los lados, interlineado doble, fuente Arial o Times New Roman de 12 puntos, texto justificado (Ver plantilla para presentación de artículos). La extensión de los artículos debe ser de alrededor de 5.000 palabras ( \pm 20 páginas, incluyendo gráficos, tablas, referencias, etc.); como mínimo 3.500 y máximo 8.000 palabras. Se debe seguir el estilo vigente y recomendado en el Manual para Publicación de la American Psychological Association (APA). (Para mayor información véase http://www.apastyle.org/)
Citas y notas al pie: las notas aclaratorias o notas al pie no deben exceder cinco líneas o 40 palabras, de lo contrario estas deben ser incorporadas al texto general. Las citas pueden ser:

Corta: (con menos de 40 palabras) se incorporan al texto y pueden ser: textuales (se encierran entre dobles comillas), parafraseo o resumen (se escriben en palabras del autor dentro del texto).

Cita textual extensa: (mayor de 40 palabras) debe ser dispuesta en un renglón y un bloque independiente con sangrías y omitiendo las comillas, no olvidar en ningún caso la referencia del autor (Apellido, año, página).

Referencias: como modelo para la construcción de referencias se emplea el estilo recomendado en el Manual para Publicación de la American Psychological Association (APA) (http://www.apastyle.org/).

Siglas: en caso de emplear siglas en el texto, las figuras o las tablas, se debe proporcionar la equivalencia completa la primera vez que se empleen y encerrarlas entre paréntesis. En el caso de citar personajes reconocidos se deben colocar nombres o apellidos completos, nunca emplear abreviaturas.

Figuras y tablas: las figuras (gráficos, diagramas, ilustraciones, planos, mapas o fotografías) y las tablas deben ir numeradas y contener título o leyenda explicativa relacionada con el tema del artículo, que no exceda las 15 palabras (Figura 1. xxxxx, Tabla 1. xxxx, etc.) y la procedencia (fuente: autor o fuente, año, página). Estas se deben referenciar en el texto de forma directa o entre paréntesis; se recomienda hacerlo con referencias cruzadas.

También se deben entregar en medio digital, independiente del texto, en formatos editables o abiertos. La marcación de los archivos debe corresponder a la incluida en el texto. Según la extensión del artículo se deben incluir de 5 a 10 gráficos. Ver guía para la búsqueda de imágenes de dominio público o bajo licencias Creative Commons (CC).

El autor es el responsable de adquirir los derechos o las autorizaciones de reproducción a que haya lugar para imágenes o gráficos tomados de otras fuentes, así como de entrevistas o material generado por colaboradores diferentes a los autores; de igual manera, se debe garantizar la protección de datos e identidades para los casos que sea necesario.

FOTOGRAFíA: pueden ser entregadas en original para ser digitalizadas, de lo contrario se deben digitaliza r con una resolución igual o superior a 300 dpi para imágenes a color y 600 para escala de grises. Los formatos de las imágenes pueden ser TIFF, PSD o JPG, y deben cumplir con las características expresadas en el punto anterior (figuras).

Planimetría: se debe entregar la planimetría original en medio digital, en lo posible en formato CAD, y sus respectivos archivos de plumas o en PDF; de no ser posible, se deben hacer impresiones en tamaño carta con las referencias de los espacios mediante numeración y lista adjunta. Deben tener escala gráfica, escala numérica, norte, coordenadas y localización. En lo posible, no deben contener textos, achurados o tramas.

Para más detalles, consultar el documento RevArq Parámetros para Autores Descripción en el portal web de la Revista de Arquitectura

\section{Beneficios}

Como reconocimiento a los autores, se les hará envío postal de dos ejemplares de la edición impresa sin ningún costo y entregada en la dirección consignada en el formato de hoja de vida (RevArq FP01); adicionalmente, se enviará el vínculo para la descarga de la versión digital.

También se enviará una constancia informativa en la que se relaciona la publicación del artículo y, de manera opcional, se pueden detallar las fechas del proceso editorial y el arbitraje realizado. 
La selección de revisores se realiza de acuerdo con los siguientes criterios:

- Afinidad temática.

- Formación académica.

- Experiencia investigativa y profesional.

- Producción editorial en revistas similares o en libros resultado de investigación.

El proceso de arbitraje se basa en los principios de equidad e imparcialidad, y en los criterios de calidad y pertinencia.

El desarrollo de la revisión se realiza según el formato (RevArq FP10 Evaluación de artículos) y las observaciones que el revisor considere necesarias en el cuerpo del artículo. En cualquiera de los conceptos que emita el revisor (Aceptar, Publicable con modificaciones, Reevaluable o No publicable), y como parte de la labor formativa y de comunidad académica, el revisor hará sugerencias para mejorar el documento. El revisor podrá solicitar una nueva relectura del artículo después de los ajustes realizados por el autor.

El revisor también deberá diligenciar el formato RevArq FP01 Hoja de Vida, con el fin de certificar y soportar el proceso de revisión ante los SIR que así lo soliciten.

En el proceso de arbitraje se emplea el método doble ciego, los nombres del revisor no serán conocidos por el autor y viceversa. Con el fin de garantizar el anonimato del autor, al artículo postulado se le han podido suprimir nombres, instituciones o imágenes que puedan ser asociadas de manera directa al autor.

Aunque se procura el anonimato, una vez recibida la invitación como par revisor del artículo, el revisor debe cerciorarse de que no exista conflicto de intereses (CDI) o alguna limitante que afecte la revisión o que pueda ser vista como tal (lazos familiares, amistad o enemistad, vínculos contractuales o laborales, posiciones éticas, etc.), de presentarse esta situación se notificara al editor. (Ver modelo RevArq FP06 CDI).

Dada la confidencialidad del proceso de revisión, y considerando los derechos de autor y de propiedad intelectual que pueda haber sobre el material que se entrega, el revisor se compromete a mantener en absoluta reserva su labor, a limitar el uso de la obra entregada solo para el propósito designado y a devolver la documentación remitida una vez concluya la actividad.

El tiempo establecido para las revisiones de pares es de máximo un mes a partir de la confirmación de la recepción de la documentación. Ese plazo podrá ser modificado de mutuo acuerdo entre el editor y el revisor, siempre y cuando no afecte la periodicidad de la revista, la impresión o el tiempo para emitir una respuesta al autor.

Los revisores se acogerán a "COPE Ethical Guidelines for Peer Reviewers" de COPE.

\section{Beneficios}

Como retribución a los revisores se les hará envío postal de un ejemplar de la edición impresa sin ningún costo y entregada en la dirección consignada en el formato de hoja de vida. También, si es de interés para el revisor, podrá hacer la solicitud de alguna de las publicaciones editadas y presentes en el catálogo de publicaciones de la UNIVERSIDAD CATÓlica de Colombia, previa aprobación de la Editorial y sujeto a la disponibilidad.

Si lo desea tendrá derecho a una constancia de la colaboración en la revisión de artículos, la cual solo contendrá el periodo en el cual se realizó la actividad. También tendrá la posibilidad de aceptar o no la publicación de su nombre, nacionalidad y nivel máximo de formación en la página web de la Revista de Arquitectura en su calidad de colaborador.

\section{A) Proceso de revisión por pares}

Luego de la postulación del artículo, el editor de la Revista de Arquitectura selecciona y clasifica los artículos que cumplen con los requisitos establecidos en las directrices para los autores. El editor podrá rechazar en primera instancia artículos, sin recurrir a un proceso de revisión, si los considera de baja calidad o por presentar evidencias de faltas éticas o documentación incompleta.

Los artículos se someterán a un primer dictamen del editor, de los editores de sección y del Comité Editorial, teniendo en cuenta:

- Afinidad temática, relevancia del tema y correspondencia con las secciones definidas.

- Respaldo investigativo.

- Coherencia en el desarrollo del artículo, así como una correcta redacción y ortografía.
- Relación entre las figuras y tablas con el texto del artículo.

En esta revisión se verificará el nivel de originalidad mediante el uso de software especializado (Ithenticate o similar) y recursos digitales existentes para tal fin, también se observará la coherencia y claridad en los apartados del documento (modelo IMRYD), la calidad de las fuentes y la adecuada citación, esto quedará consignado en el formato (RevArq FP09 Revisión de artículos); esta información será cargada a la plataforma de gestión editorial y estará a disposición del autor.

En caso de que el artículo requiera ajustes preliminares, será devuelto al autor antes de ser remitido a revisores. En este caso, el autor tendrá veinte días para remitir nuevamente el texto con los ajustes solicitados.

Después de la preselección se asignan mínimo dos revisores especializados, quienes emitirán su concepto utilizando el formato (RevArq FP10 Evaluación de artículos) y las anotaciones que consideren oportunas en el texto; en esta etapa se garantizará la confidencialidad y el anonimato de autores y revisores (modalidad doble ciego).

Del proceso de revisión se emite uno de los siguientes conceptos que será reportado al autor:

- Aceptar el envío: con o sin observaciones.

- Publicable con modificaciones: se podrá sugerir la forma más adecuada para una nueva presentación, el autor puede o no aceptar las observaciones según sus argumentos. Si las acepta, cuenta con quince días para realizar los ajustes pertinentes.

- Reevaluable: cumple con algunos criterios y debe ser corregido. Es necesario hacer modificaciones puntuales y estructurales al artículo. En este caso, el revisor puede aceptar o rechazar hacer una nueva lectura del artículo luego de ajustado.

- No publicable: el autor puede volver a postular el artículo e iniciar nuevamente el proceso de arbitraje, siempre y cuando se evidencien los ajustes correspondientes.

En el caso de presentarse diferencias sustanciales y contradictorias en los conceptos sobre la recomendación del revisor, el editor remitirá el artículo a un revisor más o a un miembro del Comité Editorial quien podrá actuar como tercer árbitro, con el fin de tomar una decisión editorial sobre la publicación del artículo.

Los autores deberán considerar las observaciones de los revisores o de los editores, y cada corrección incorporada u omitida debe quedar justificada en el texto o en una comunicación adjunta. En el caso que los autores omitan las indicaciones realizadas sin una argumentación adecuada, el artículo será devuelto y no se dará por recibido hasta que no exista claridad al respecto.

El editor respetará la independencia intelectual de los autores y a estos se les brindará el derecho de réplica en caso de que los artículos hayan sido evaluados negativamente y rechazados.

Los autores, con su usuario y contraseña, podrán ingresar a la plataforma de Gestión Editorial, donde encontrarán los conceptos emitidos y la decisi sobre el artículo.

El editor y el Comité Editorial se reservan el derecho de aceptar o no la publicación del material recibido. También se reservan el derecho de sugerir modificaciones de forma, ajustar las palabras clave o el resumen y de realizar la corrección de estilo. El autor conocerá la versión final del texto antes de la publicación oficial del mismo.

Cuando un artículo es aceptado para su publicación, el autor debe firmar la autorización de reproducción (RevArq FP03 Autorización reproducción). Para más información ver: Política de derechos de autor

\section{Notas aclaratorias:}

La Revista de Arquitectura publica un número limitado de artículos por volumen y busca el equilibrio entre las secciones, motivo por el cual, aunque un artículo sea aceptado o continúe en proceso de revisión, podrá quedar aplazado para ser publicado en un próximo número; en este caso, el autor estará en la posibilidad de retirar la postulación del artículo o de incluirlo en el banco de artículos del próximo número.

El editor y los editores de sección de la Revista de Arquitectura son los encargados de establecer contacto entre los autores y revisores, ya que estos procesos se realizan de manera anónima.
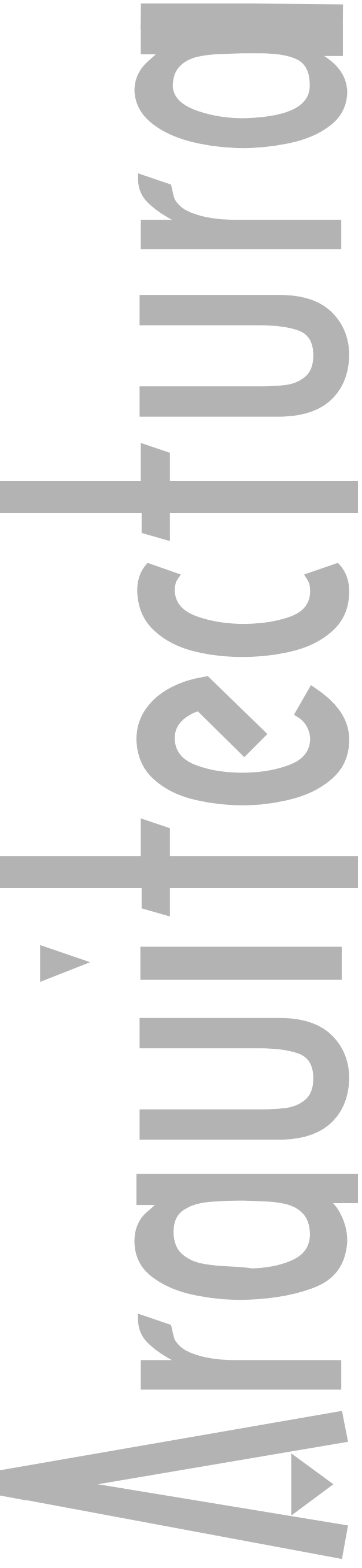
Estructura de indicadores de habitabilidad del espacio público en ciudades latinoamericanas

ن Structure of indicators of public space habitability in Latin American cities

Pablo Páramo,Andrea Burbano, Diana Fernández-Londoño

Além do público/privado

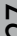
no Rio de Janeiro

Más allá de lo público y lo privado. Intervenciones temporales y creación de espacios colectivos en Río de Janeiro

Beyond the public and the private. temporary interventions and the creation of collective spaces in Rio de Janeiro

Conservar o renovar: dinámicas de histórico de tres

ciudades intermedias patrimoniales

U Una mirada a través de las licencias urbanísticas

To preserve or to renovate: Construction dynamics in the historic center of three intermediate-sized heritage cities. A look through urban planning permits

\section{Lida Buitrago-Campos}

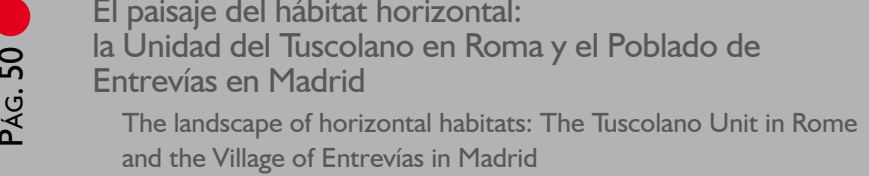

Evolución paralela del relato fílmico y la arquitectura de ㅇ. los cines entre 1900 y 1930

Atención especial al caso españo

¿ Parallel evolution of cinematographic stories and the architecture of cinemas between 1900 and 1930, with a special attention to the Spanish case

\section{Ana C. Lavilla-Iribarren}

El plan, acto mesiánico del proyectista

- La situación histórica del diseño en la utopía

₹. modernizante

The plan, a messianic act of the project architect. The historica situation of design in the modernizing utopia

Resiliencia a inundaciones: nuevo paradigma para el diseño urbano

ن Flood resilience: A new paradigm for urban design

¿ Resilience to flooding: new paradigm to urban design

Luis Fernando Molina-Prieto

Acceso solar en la arquitectura y la ciudad

ผ

Aproximación histórica

Solar access in architecture and the city. Historical approach

这

Campus universitario sustentable

ô

Sustainable university campus

نำ

Lina Johanna Zapata-González,Andrés Quiceno-Hoyos,
Luisa Fernanda Tabares-Hidalgo

La crítica arquitectónica como objeto de investigación

[La critique architecturale, objet de recherche]

Architectural criticism as an object of research

ن் Hélène Jannière 